\title{
Individual Swift Trust and Knowledge-Based Trust in Face-to-Face and Virtual Team Members
}

\author{
LIONEL P. ROBERT JR., ALAN R. DENNIS, AND \\ YU-TING CAISY HUNG
}

LIONEL P. ROBERT JR. is an Assistant Professor of Information Systems at the University of Arkansas, Fayetteville, Sam M. Walton College of Business. His research focuses on team collaboration in virtual environments. He was a BAT doctoral fellow and KPMG scholar at Indiana University, where he completed his Ph.D. in Information Systems. Dr. Robert has published in Information Systems Research, Journal of Quality Management, and IEEE Transactions on Professional Communication, as well as conference proceedings, including the International Conference on Information System (ICIS), Hawaii International Conference on System Sciences (HICSS), and Academy of Management Conference (AOM). He currently serves on the editorial board of IEEE Transactions on Professional Communication.

Alan R. Dennis is a Professor of Information Systems and holds the John T. Chambers Chair of Internet Systems in the Kelley School of Business at Indiana University. He is a senior editor at MIS Quarterly and the founding publisher of MIS Quarterly Executive. Professor Dennis has written more than 100 research papers, focusing on four themes: the use of information technologies to support team creativity and decision making, knowledge management, the use of the Internet to improve business and education, and professional issues facing IS academics. He has also written four books, two on data communications and networking and two on systems analysis and design.

Yu-Ting Caisy Hung is a Research Associate in the E. Philip Saunders College at the Rochester Institute of Technology. Previously, she was an Assistant Professor in the Department of Information Systems at the National University of Singapore. She received her B.B.A. in management information systems from Chun-Yuan Christian University in Taiwan, her M.Sc. in information systems from the University of Maryland, and M.B. and Ph.D. in information systems from Indiana University. Her primary research focuses on virtual team interaction through various information and communication technologies. Her specific research areas include intercultural communication and collaboration in global virtual teams, temporal coordination in virtual teams, and trust in virtual teams. She has presented her work in various international conferences and has published in Journal of Management Information Systems, IEEE Transactions on Professional Communication, Communications of the ACM, and Small Group Research.

AвSTRACT: Traditionally, trust has been seen as a result of personal knowledge of an individual's past behavior. In this view, trust develops gradually over time based on an individual's cognitive assessment of the other person's behavior. However, high levels 
of trust have been observed among members of virtual teams, who often have little prior history of working together and may never meet each other in person. To integrate these two seemingly contradictory views of trust, this study manipulated team member characteristics and team member behavior to empirically test a two-stage theoretical model of trust formation and the influence of information and communication technologies (ICT) on trust formation. The results indicate that category-based processing of team member characteristics and an individual's own disposition to trust dominated the initial formation of swift trust. Once individuals accumulated sufficient information to assess a team member's trustworthiness, the effects of swift trust declined and knowledge-based trust formed using team members' behaviors (perceived ability, integrity, and benevolence) became dominant. The use of ICT increased perceived risk of team failure, which reduced the likelihood that team members would engage in future trusting behaviors.

KEY WORDS AND PHRASES: cognitive trust, computer-mediated communication, initial trust, knowledge-based trust, presumptive trust, swift trust, trust, vignettes, virtual team.

TRUST IS AN ESSENTIAL ELEMENT in both organizational and team phenomena. Trust affects performance $[53,59,71]$, and even more so when tasks are highly interdependent [2, 67]. Trust is a critical element in enhancing intra- and interorganizational cooperation, coordination, and control $[64,77,94]$. Trust allows individuals to justify their decision to contribute $[15,76,78]$ and allows individuals to freely exchange information and share knowledge that is critical to the success of collaboration $[35,60]$. Trust is even more important in virtual teams, in which members communicate mainly through information and communication technologies (ICTs) and are often geographically dispersed. Traditional control mechanisms imported from a face-to-face communication environment have been shown to be less effective in an ICT-mediated communication environment [114]; thus, control based on authority is often yielded to self-direction and self-control [53], which relies heavily on trust.

Trust is an individual-level construct and is often defined as an individual's willingness to be vulnerable to the actions of another person [94]. Trust has traditionally been seen as the result of individual judgments of past behavior in which derived costs and benefits of such future behavior are cognitively assessed [75, 149]. Based on positive outcomes of repeated behavior, individuals develop trust gradually over time $[6,82,94]$. This traditional view of trust would predict low levels of initial trust in virtual teams because team members have little past history, may not share common cultures, and use ICT extensively, which can limit direct personal observations that allow members to perform effective cognitive trust assessment [21, 116]. However, high levels of initial trust called swift trust have been observed among members of temporary teams [99] and virtual teams [61, 63].

We believe that these seemingly contradictory views of trust call for a reexamination of trust formation. First, we argue that these two views of trust-knowledge-based trust developed through interactions and swift trust developed prior to interaction-are 
two different forms of trust that are formed through fundamentally different processes. Unlike previous empirical studies of trust in virtual teams [61, 63, 67], we follow McKnight et al. [98] and Meyerson et al. [99] and treat swift trust as a categorymatching process based on team member characteristics, not on their behaviors, and thus we measure swift trust prior to any knowledge of team members' behavior. Knowledge-based trust is based on the assessment of behavior and thus we measure it after subjects have been exposed to past behaviors of future team members.

Second, we agree that initial swift trust perceptions are fragile [83, 98, 99], but we argue that these initial, fragile — and often wildly inaccurate-perceptions have a greater impact on subsequent trust than previously believed. These initial judgments influence how individuals perceive the outcomes of a trusting behavior and how they interpret behaviors that either support or refute that judgment $[10,75,153]$.

Finally, we argue that the communication environment through which team members interact (face-to-face or ICT mediated) influences a team member's willingness to engage in trusting behavior. ICT environments slow the relationship development processes [2, 18, 26, 143, 145] and lack traditional monitoring mechanisms (e.g., direct supervision), which reduces the sense of social control and coordination [63, 114]. Both of these factors increase the perception of risk associated with team outcomes.

\section{Prior Theories and the Proposed Model}

\section{Cognitive Trust}

THE INFORMATION SYSTEMS (IS) LITERATURE alone offers a diversity of definitions of trust. This is in part due to the many different IS contexts in which trust has been studied. Researchers have studied trust in online purchasing [7, 32, 70, 87], the use of recommendation agents $[72,73,74,146]$, and virtual health-care settings $[81,112,152]$. In this study, we focus on interpersonal trust among members of virtual teams.

Although there are many types of virtual teams, three factors commonly differentiate virtual teams from face-to-face teams: the limited history of team members, the temporary nature of the teams, and the use of electronic communications as a primary communication medium. Interpersonal trust can be categorized as cognitive, affect, and emotional $[72,73]$. Like prior research on virtual teams, this study focuses on cognitive interpersonal trust [61, 63, 64, 67].

Cognitive trust is defined as a "trustor's rational expectations that a trustee will have the necessary attributes to be relied upon" [77, p. 943]. Cognitive trust can be developed through at least two paths. One, trust can be imported "swiftly" from previous experiences and invoked by similarities in the current situation/trustee with that of the past [99]. Two, trust can emerge as the result of personal experiences between the trustor and the trustee [94]. The first path is referred to in this paper as swift trust and the second as knowledge-based trust. In this study, we differentiate between trusting beliefs (the belief the trustor has toward the trustee) and trusting intention (willingness of the trustor to engage in trusting behavior with the trustee), regardless of the path through which trust is formed $[73,98]$. 
In particular, we adopt Mayer et al.'s definition of trust as "the willingness of a party to be vulnerable to the actions of another party based on the expectation that the other will perform a particular action important to the trustor, irrespective of the ability to monitor or control that other party" [94, p. 712]. Traditional models of trust have viewed trust as a developmental process closely intertwined with the relationship development process $[83,134]$. Trust is viewed as a result of a history-dependent relationship [75] that develops gradually through the communication of past behavior $[82,94]$. Traditional trust development theories describe a deliberate cognitive process in which one party's trustworthiness and the level of perceived risk of a given situation are compared [94]. Through a sequential iteration, the achievement of trust at one level is theorized to enable the development of trust at the next level [82].

There are at least three reasons members of temporary systems such as virtual project teams in which members interact primarily through ICT and media other than face-toface communication could experience difficulties in developing trust. First, the lack of past experience (such as well-developed personal relationships or shared norms of obligations and responsibilities in shared social networks) will limit the amount of information on which team members can base their judgments about their team member's trustworthiness $[13,120]$. Second, the geographical dispersion may introduce diversities in cultures or organizational rules and norms that reduce the likelihood of building trusting personal relationships based on individual similarities [13, 94]. Third, the reliance on ICT-mediated communication in virtual team collaboration has been found to slow down the development of personal relationships critical to trust building $[2,18,26,143,145]$. As a result, the traditional view of knowledge-based trust will predict low levels of initial trust among virtual team members.

However, high levels of trust have been observed in initial encounters in organizations [98], as well as in temporary traditional [99] and virtual teams [61, 63]. The high initial trust observed in these systems is called swift trust, a form of trust that is conferred "ex ante" [99]. Swift trust allows individuals to manage issues of vulnerability, uncertainty, risk, and expectations in situations where a developed trusting relationship is absent [99]. This form of depersonalized trust develops quickly, even before members of a team have chances to interact with each other [99].

These two views of trust formation seem to contradict: on one hand, trust is a timeconsuming process involving sequential iterations of observable past behavior [75, $82,94]$, while on the other hand, trust can be imported and given "ex ante" among individuals with no prior history $[61,63,98,99]$. We argue that neither view by itself is complete and understanding how the two views interrelate can lead to a more complete view of trust formation in virtual teams. Thus, we argue that these two views of trust represent two forms of trust developed via different processes, typically at different stages of a relationship.

We propose that during initial interactions, virtual team members do not have sufficient personal knowledge of each other's past behavior to deliberately assess trustworthiness. At this stage, team members are forced to rely on category-based information processing. When team members engage in category-based information processing, they view their team members as members of a category rather than as 
individuals $[24,45]$. Team members place other team members into categories based on their characteristics (e.g., gender, profession, or organizational role) and form judgments based on that individual's category and not his or her actual behaviors [99]. An individual's own personal disposition to trust and the general trust associated with the category into which the team member has been assigned are used to form an initial swift trust judgment [97]. This depersonalized attribution process allows individuals to make a rapid trust judgment without personal knowledge of their team members' behavior [99].

Once a team member acquires personal knowledge about another team member's behavior, he or she is more likely to effectively assess their team member's ability, integrity, and benevolence and determine whether or not this team member is trustworthy $[94,97]$. At this point, the bases of a trust judgment are shifted from disposition to trust and category-based processing of characteristics to personal-based cognitive processing in which the individual's behaviors (e.g., ability, integrity, and benevolence) are deliberately assessed.

We also posit that communication environments-face-to-face or ICT mediatedwill have an indirect effect on trust by influencing how a team member perceives the level of risk involved in the situation. The difference between trust belief and perceived risk will influence an individual's trust intention [94]. We argue that communication primarily through ICTs will increase a virtual team member's perceived risk and, hence, indirectly decrease the team member's trust intention and trust behavior. The following subsections present the theoretical model and hypotheses (see Figure 1).

\section{Swift Trust}

Swift trust, a presumptive form of trust, was introduced to explain the paradoxical trusting behavior exhibited by members of new temporary project teams [99, 151]. In these temporary teams, individuals who had no past working relationships immediately formed trust and began engaging in trusting behaviors. These individuals did not have a past track record or time to wait to develop one before working together. It was posited that these individuals imported trust from other contexts $[99,151]$. We believe that five of the six bases of trust offered by Kramer [75] are what individuals import from other contexts to influence their formation of swift trust. These five are role-based trust, rule-based trust, third-party recommendation-based trust, dispositional-based trust, and category-based trust.

In this paper, we examine only the last two factors that we posited will influence the formation of swift trust: an individual's disposition to trust (also called propensity to trust) and category-based trust. As a result, we will give a brief overall of the first three and then limit our discussion to disposition to trust and category-based trust for the remainder of the paper. Role-based trust is based on the use of simple heuristics about the role the other team member plays (e.g., if he or she is an accountant, he or she must be good with numbers) in the absence of personalized knowledge about him or her [8]. Rule-based factors such as the situational normality and organizational/ team structures [98], explicit and tacit understandings regarding transaction norms, 


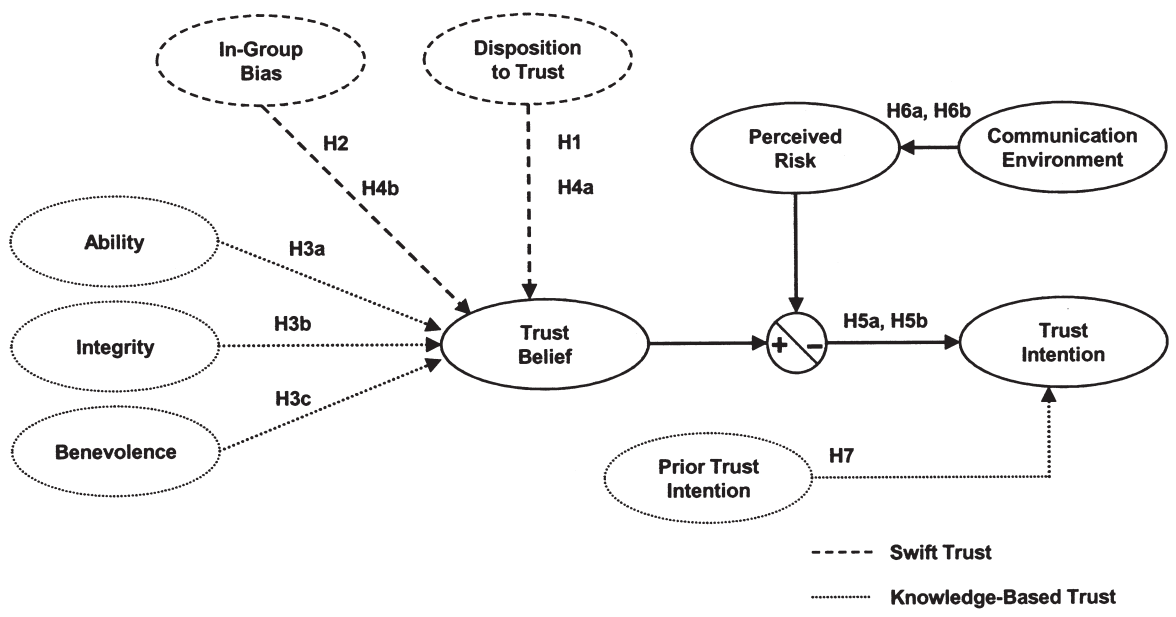

Figure 1. The Proposed Model of Trust Formation

interaction routines, and exchange practices provide another basis for inferring others' behavior in the absence of personal knowledge $[43,92]$. Third parties can also play a role in the formation of trust, enabling team members to "roll over" their trust from well-established relationships to others with whom they lack adequate knowledge to form their own trust judgments (e.g., "if Bob trusts him, I trust him") $[19,141]$.

Disposition to trust is a "generalized attitude" learned from both personal experience of fulfilled and unfulfilled promises as well as through direct observed behavior of early caregivers [126] and refers to one's general predisposition to trust or distrust other people $[52,94,137]$. Although disposition to trust is "akin to a personality trait" and in some cases has been treated as one [94], it is a general tendency resulting from past experiences $[98,126,127,128]$. Dispositional trust is posited to have a greater influence on an individual's trust belief before any relevant information about a team member's past behavior is available [94, 97]. Disposition to trust has been shown to have a direct positive relationship with trust $[4,63]$. Hence, it is hypothesized that

Hypothesis 1: Before an individual gains personal knowledge about a team member's behavior, his or her own general disposition to trust will directly influence his or her trust belief toward the other team member.

Meyerson et al. [99] argue that the lack of personal knowledge coupled with the need to engage in trusting behaviors immediately to perform their job leads individuals to use category-driven information processing as a way to manage issues of vulnerability, uncertainty, risk, and expectations. In this process, individuals mentally place others into a category and derive trust based on how much they trusted members of that category $[63,80,99]$. In some cases, this category processing is spontaneously activated without conscious thought (i.e., via automaticity), while in other cases, individuals may actively place others into categories [24, 25, 89]. 
Category-based trust is often based on cultural or identity-based stereotypes of teammates $[15,44,99,151]$. These categories can be based on previous long-term associated groups such as race and gender or on ad hoc factors such as shirt colors or random assignments to groups [106]. Category processing treats individuals as members of a category rather than as individuals $[24,45]$. This allows team members to act according to general principles and practices associated with certain categories. The significance of category processing in forming initial trust is also emphasized in McKnight et al.'s [98] model of initial trust. Category-based processing influences the swift formation of trust.

Identification with a salient social or organizational group (e.g., gender, race) influences swift trust formation $[15,98,99]$. Group identification, the degree to which one identifies with a group, is a result of category-based information processing in which an individual identifies him- or herself as a member of a categorical group [1, 88, 138, $139,140,147]$. Strong group identification can lead group members to form a positive bias and ascribe positive attributes to members of their own group [8, 56, 122, 138]. One of those positive attributes is trust. Past research has shown that individuals are more likely to trust people they believe are similar to them (e.g., in-group members) $[14,16,37,100,148]$. When an individual believes that a team member is similar to him- or herself (e.g., in-group member), in the absence of any information about that team member's past behavior, he or she will assume a favorable bias that will positively affect swift trust. This process is amplified in ICT environments where personal cues are minimal [144]. Therefore,

Hypothesis 2: Before an individual gains personal knowledge of a team member, his or her in-group bias toward the other person will directly influence his or her trust belief of that person.

\section{Knowledge-Based Trust}

According to the traditional view of knowledge-based trust, trust involves deliberate cognitive assessment of relevant attributes of the trustee [94]. The integrated model of trust proposed by Mayer et al. [94], one of the more broadly adopted traditional models of trust $[9,38,110]$, argues that trust is a function of an individual's perceptions of the other person's trustworthiness determined by his or her perceived ability, integrity, and benevolence $[22,93,94]$. Integrity is the adherence to a set of acceptable principles. Integrity is important to trust because it suggests the extent to which the trustee's actions are likely to follow his or her espoused intentions $[63,94]$. If the trustor believes that the trustee is likely to do what he or she says he or she will do, trust will increase. Ability is the task-related skills that enable an individual to be perceived as competent within some specific domain. Ability is critical to trust because the trustor needs to be assured that the trustee is capable of performing the task he or she is being trusted to do $[63,94]$. If the trustor believes the trustee is not able to perform the task, then trust will decrease. Benevolence is the extent to which an individual is believed to feel interpersonal cares and concerns for others and to be willing to do "good" aside 
from an egocentric profit motive. Benevolence is important (especially over the long term) because it suggests that the trustee has some attachment to the trustor, over and above the specific situation or transaction in which trust is being conferred [63,94]. If the trustor believes the trustee is benevolent, then trust will increase (especially over the long term). Therefore,

Hypothesis 3: Once an individual accumulates sufficient knowledge to develop perceptions of a team member's (a) ability, (b) integrity, and (c) benevolence, these perceptions will directly influence his or her trust belief.

Individuals will have difficulties performing effective assessment of their team members' trustworthiness until they have accumulated some knowledge of their ability, integrity, and benevolence. In other words, knowledge about other virtual team members' relevant past behavior is needed before a knowledge-based assessment of their trustworthiness can be calculated. Once an individual accumulates sufficient personal knowledge of a team member's past behavior, he or she will be more likely to engage in a knowledge-based assessment regarding the team member's trustworthiness because a knowledge-based assessment is likely to produce a more accurate judgment than an assessment using category-based swift trust. As a result, once an individual gains enough knowledge of the other person, the antecedents of category-based swift trust will no longer be significant predicators of trust. Hence,

Hypothesis 4: Once an individual accumulates sufficient knowledge to develop perceptions of a team member's ability, integrity, and benevolence, the influence of his or her (a) disposition to trust and (b) in-group bias on trust belief will become insignificant.

\section{Perceived Risk}

Perceived risk, a personal assessment of the likelihood of a significant disappointing outcome [135], has been identified as an essential element of trust [94, 129]. Perceived risk has been proposed to be the key factor that differentiates one's trust belief and trust intention - the difference between an individual's willingness to assume risk and actually assuming risk $[90,94,113]$. Trust, as one's willingness to be vulnerable to the interacting parties, increases the likelihood that an individual is willing to engage in trusting behavior. However, the perceived risk inherent in the behavior is also critical in determining whether or not a specific action will be taken [90]. Therefore, in addition to the attributes of the team members, one also needs to assess factors outside the relationship that make the decision significant and uncertain [94]. Perceived risk is situational and involves the assessment of possible losses and gains embedded in the interaction context [11]. Perceived risk for team members involves the assessment of potential team failure.

According to Mayer et al., "the level of trust is compared to the level of perceived risk in a situation. If the level of trust surpasses the threshold of perceived risk, then the trustor will engage in the RTR [risk taking in relationships]. If the level of per- 
ceived risk is greater than the level of trust, the trustor will not engage in the RTR" [94, p. 726]. An individual's perceived risk of the situation is posited to regulate the relationship between one's trust belief and trust intention [90, 94, 153]. The level of trust is compared to the level of perceived risk, and if risk is higher than trust, team members will be less likely to engage in trusting behavior. However, if the level of perceived risk is lower than the level of trust, team members will be more likely to engage in trusting behavior.

Hypothesis 5: The difference between trust belief and perceived risk will positively influence one's intention to engage in trusting behavior (a) during the initial formation of swift trust and $(b)$ in the later stages of a knowledge-based trust.

\section{Communication Environment and Risk Assessment}

Communication environment is posited to have an indirect influence on trust intention through the impact of a virtual team member's perceived risk of the situation. Given that knowledge-based trust is highly dependent on the level of personal knowledge about past behavior, slower development of personal relationships indicates that one may need longer time before one can perform an effective and accurate cognitive-based trust assessment of virtual team members. The developmental differences between face-to-face teams and ICT-mediated teams have been well documented [2, 18, 26, $143,145]$. Hence, we propose that individuals may perceive higher levels of risks in team projects when their communication and collaboration with virtual team members from different locations is primarily through the use of ICTs, for two reasons.

First, the traditional monitoring mechanisms for maintaining a sense of social control and coordination, such as direct supervision, geographical collocation, similar backgrounds, and shared experiences, are often missing in ICT-mediated communication environments when virtual team members are drawn from different locations [63, 114]. This lack of ability to closely monitor and control the work of others may lead to a higher perception of risk $[22,34]$, mainly due to the fear that other team members may engage in absenteeism and social loafing, which are often observed in short-term ICT-mediated virtual team collaboration $[63,108]$. Therefore, it is hypothesized that due to the lack of ability to closely monitor and control the actions of the other team members in an ICT-mediated virtual team communication environment, individuals will perceive higher levels of risk.

Second, team diversity, lack of shared norms, and temporal and geographic dispersion $[61,63]$ present other sources of risk. Team diversity, because members are drawn from different locations, can lead to miscommunications between team members [39]. Shared norms, which can facilitate the exchanging of information without the need for explicit communication [125], are often missing in virtual teams whose members are drawn from different locations. Temporal dispersion is normally associated with asynchronous team communications, which involve some time lag between exchanges $[61,124,143]$. The longer time requirement for communication and the lack of prompt response and feedback could lead individuals to assume the worst about their team 
members [31], an attitude that is very likely to slow or impair the development of trust $[69,96]$. This is consistent with the observation that zero-history teams interacting face-to-face exhibited higher levels of trust and exchanged more information than zero-history ICT-mediated teams [2]. In general, collaboration through virtual environments presents higher uncertainty and risk to collaborators [29].

Hypothesis 6: An ICT-mediated environment will increase an individual's perceived risk (a) during the initial formation of trust and $(b)$ in the later stages of a trust relationship.

\section{Prior Trust Intention}

Initial judgments and expectations influence how individuals perceive the outcomes of a trusting behavior and how they derive meaning from and ascribe personal characteristics to them $[23,24,121]$. As a result, individuals' assessment of their team member's future trust behavior is influenced by their prior trust judgments and expectations of their team member's behavior. The assessment and interpretation of the meaning of a behavior may vary across individuals; selective perception is a bias in information processing that often leaves individuals who view the same events with different interpretations of those events [55, 68]. Individuals focus on the information that supports their initial judgments and discounts information that opposes them [85, 142]. Thus, initial judgments color how an individual perceives a behavior, and how he or she derives meaning and ascribes personal characteristics from it [23, 24, 121]. As a result, an individual's initial trust judgment will influence how the individual forms subsequent trust judgments.

In other words, trust is affected not only by the outcomes of a trusting behavior but also by the extent to which the outcomes match the trustor's initial judgment about trust $[10,12,75,153]$. Therefore, swift trust judgments made during the initial formation of trust may have a "leftover" effect on the subsequent trust judgments. Although personal knowledge drives the formation of knowledge-based trust, prior trust judgments may influence the way in which the outcomes are perceived and personal knowledge is interpreted [64].

Hypothesis 7: Trust intentions formed using swift trust will have a positive direct effect on knowledge-based trust intentions in the later stages of a trust relationship.

\section{Methodology}

\section{Participants}

A tOTAL OF 203 UNDERGRADUATE BUSINESS STUDENTS at a large U.S. public state university participated in this study. Their participation was voluntary and they received course credit for their participation. The average age of the participants was 22 years and 64 percent were female. 


\section{Tasks}

The tasks were implemented through the use of vignettes. Vignettes are "stories about individuals, situations and structures which can make reference to important points in the study of perceptions, beliefs and attitudes" [57, p. 381]. Vignettes can be viewed as simulations of real events [50]. Vignettes, although used relatively infrequently in the IS field [30, 48, 54, 62], are a valid experimental technique for the study of perceptions, beliefs, and attitudes [57, 101, 115]. Vignettes are used in management, social psychology, and economic studies [5, 36, 104, 132]. Vignettes have been used in numerous studies of trust (e.g., [20, 40, 102]) and in the study of collaboration (e.g., $[3,28,62])$. For example, much of the research on media richness is based on the use of vignettes (e.g., [33, 41, 130]).

The use of vignettes offers three advantages as a research technique. One, vignettes reduce response bias from subjects on topics that tend to elicit socially desirable responses $[54,58]$. This was important in this particular study because our research model included group bias as an independent variable. If subjects were asked similar questions toward "real people," they might have responded in a politically correct manner. Two, vignettes allow researchers to manipulate variables and personalize situations $[30,50]$. This allowed us to place the subjects in a familiar context. We did not have to ask our student subjects to pretend to be anything other than students. Three, and most important for experimental research, vignettes allow researchers to control extraneous variables and standardize the information presented to all subjects $[50,79]$. This was particularly important because we wanted to understand the cognitive process individuals used to switch between swift trust and knowledge-based trust without the inherent variability in behavior associated with "real" teams.

In order for vignettes to be effective, they have to "genuinely portray the phenomenon of interest" [50, p. 210]. Several guidelines have been offered as an approach to establish external validity in vignettes $[46,50,86]$. The recommended guidelines can all be integrated into a three-step validation procedure. Step 1: the scenarios in the vignettes should be drawn from existing literature or case study. Step 2: vignettes should be scrutinized by outside reviewers for content validity. Step 3: the vignettes should be pretested and refined before used in the actual study.

The context and content of our vignettes were derived from prior published studies involving virtual teams $[61,63,114]$. In particular, we focused our attention on the behaviors of teammates that were deemed to indicate high ability, integrity, and benevolence. The original vignettes were presented to three graduate students who were blind to our hypotheses but were familiar with the literature on trust and virtual teams and who themselves had been on at least one student team project. We had two objectives when designing the vignettes - to present a realistic scenario and to create sufficient variability in the exogenous constructs.

In order to accomplish the second objective, we manipulated the behavior in each candidate such that each one would be the highest in at least one antecedent of trust. Each graduate student read the vignette and rated each candidate on ability, integrity, and benevolence. Feedback indicated that the situation and narratives resembled that of real student team projects but changes needed to be made to decouple some of the 
antecedents of trust (ability, benevolent, and integrity) among the characters. The vignettes were modified and presented to the same graduate students. The graduate students again rated each character on each antecedent of trust. The results indicated that the graduate students rated each character high on the predicated antecedent of trust. A pilot study was conducted with 101 subjects. Feedback from the subjects during brief interviews indicated that the subjects felt that the vignettes were realistic. Subjects were also able to determine which character was the highest on each antecedent of trust.

The vignette consisted of three phases (the Appendix provides one of the vignettes we used). The first phase provided information about the team project (such as the deliverables, due date, percentage points of the student's grade) and information about the personal characteristics of the three characters in the vignette (Tom, Jane, and Peter) who were about to engage in the team project. All three characters were portrayed as undergraduate students with similar backgrounds, education levels, and majors.

The second phase was the communication between the characters as they worked on the team project. Two versions of the vignette were used to produce the experimental manipulation: one depicted characters communicating face-to-face and the other through ICT (i.e., e-mail among geographically and temporally distributed team members). Both communication scripts consisted of the same three characters stating the exact same remarks verbatim. The face-to-face version described the text as a series of three face-to-face team meetings over two weeks, while the virtual team version listed the same text as a series of e-mail messages over two weeks among students on a virtual team.

The third phase provided information about the risk associated with the project. It described a future project similar to the one in phase 1 with the same three characters. It provided information about the team project such as the deliverables, due date, the amount of percentage points associated with the student's grade, and whether the team was going to communicate face-to-face or through ICTs.

The participants were asked to perform two tasks. The first was to assess the level of perceived risk involved in the team project and their level of trust toward all three members of the project. This assessment was based solely on the characteristics of the team members and the team task (i.e., swift trust) provided in the first phase of the vignette. The second was a reassessment of the level of perceived risk and trust based on additional information about team members' behaviors (i.e., knowledgebased trust) provided in the second phase of the vignette and a new project presented in the third phase of the vignette.

\section{Independent Variables}

There were six independent variables in this study: disposition to trust, communication environment, ability, benevolence, integrity, and in-group bias. Disposition to trust was not manipulated but was measured using items adapted from Jarvenpaa et al. [63] and Schoorman et al. [131]. The communication environment was manipulated by describing the communication as occurring either face-to-face or through e-mail 
messages among geographically and temporally distributed team members. The two vignettes were identical in their description of team members but varied in the communication environment required for the project. Communication environment was measured using a zero-one indicator variable. In-group bias was measured using items from Brown et al. [17] and Otten and Moskowitz [109].

The remaining three variables (ability, benevolence, and integrity) are perceptions. Our experimental materials were designed to induce different perceptions of ability, benevolence, and integrity among the three characters in order to create variability among the characters and reduce multicollinearity. These perceptions were then measured and served as the independent variables, not the manipulations themselves. In other words, rather than presuming that the behaviors we designed to induce perceptions of high or low ability, integrity, and benevolence worked, we instead measured the actual perceptions induced and used those perceptions in our model. After all, it is the perceptions that matter in the formation of trust, not the behaviors that induced them.

Perceptions of each character's ability, benevolence, and integrity were manipulated through their behaviors in the vignettes. The vignettes were designed such that each character exhibited different levels of ability, integrity, and benevolence. To accomplish this, we designed the vignettes in such a way that each character would be high in one of the antecedents of trust (e.g., ability, integrity, or benevolence) and vary in the other two antecedents of trust. This was done to create variability in the exogenous constructs. If we did not do this, we would run the risk of having characters perceived as either high in all three antecedents or low in all three antecedents, resulting in insufficient variability.

Jane was depicted as high in integrity, Peter was high in ability, and Tom was high in benevolence. In the vignettes, Jane fulfilled her promises to the team but produced outcomes that contained errors. Peter, who possessed high technical competence, successfully completed his assigned task but displayed no concern for the team and did not complete his tasks on time. Tom demonstrated a sense of caring for other members in the team throughout the duration of the project but exhibited little ability and integrity. In order to ensure that the behaviors described in the vignettes induced participants to perceive differences in the three attributes, two pilot studies were conducted to pretest the vignettes. The vignettes were revised based on the results of the pilot tests. The perceptions of each character's ability, benevolence, and integrity were measured using items adapted from Jarvenpaa et al. [63] and Schoorman et al. [131].

In-group bias was manipulated through the use of a cover story that followed the procedure employed by Otten and Moskowitz [109]. Before the participants received the vignette, they were asked to complete a "perceptual style test" that would determine their mental orientation toward processing information either as a "grounding-oriented person" or a "figural-oriented person." The students were informed that groundingoriented individuals focus first on global impression before adding details to the larger picture, while figural-oriented individuals focus on salient features of a stimulus first and examine global characteristics later [31]. The perceptual-style test asked participants to report which image they saw first in a series of eight optical illusions taken 
from Escher [42]. All participants (regardless of their answers) were informed that they were "grounding oriented." One of the students in the vignette (Tom) was also identified as grounding oriented, while the two remaining students were labeled as figural oriented. This was done to create identification with Tom.

\section{Dependent Variables}

There were three dependent variables. Items developed by Sitkin and Weingart [136] were used to measure the level of risk perceived by the participants. Trust belief was taken from McAllister [95] and trust intention was measured using items adapted from Jarvenpaa et al. [63], Mayer and Davis [93], and Schoorman et al. [131]. It should also be noted that prior trust intention in the second model was the trust intention from the first model. Mayer et al. argue that it is the difference between trust and risk that influences trust intention:

We propose that the level of trust is compared to the level of perceived risk in a situation. If the level of trust surpasses the threshold of perceived risk, then the trustor will engage in the RTR. If the level of perceived risk is greater than the level of trust, the trustor will not engage in the RTR. [94, p. 726]

Therefore, to be consistent with H5 and with the Mayer et al. [94] model of trust, we utilized the difference score between trust belief and perceived risk to predict trust intention. (An alternative would have been to model trust belief and perceived risk as separate predictors of trust intention, but this would not have been true to our hypothesis or the Mayer et al. model, which argues that it is the difference between these two, not their independent effects, that influences trust.) The first step was to average the items for trust belief and for perceived risk. The difference score was calculated by subtracting the average trust belief score from the corresponding average perceived risk score. This single-factor difference score was then used in the partial least squares (PLS) model as the predictor of trust intention. Difference scores have also been used in prior IS research [66, 107].

\section{Control Variables}

The subject's age and gender were added as control variables for two reasons. One, age and gender were found to significant predictors in the pilot study. Two, prior research has shown that gender and age can impact perceptions of interpersonal trust $[65,95$, 119]. As a result, we included gender and age as control variables in this study.

\section{Procedures}

Upon arriving at the lab, each participant was assigned to a computer and placed in an individual cubicle. They were then instructed to go to an interactive Web site that guided them through the experiment. Figure 2 presents the overview of the procedure. 


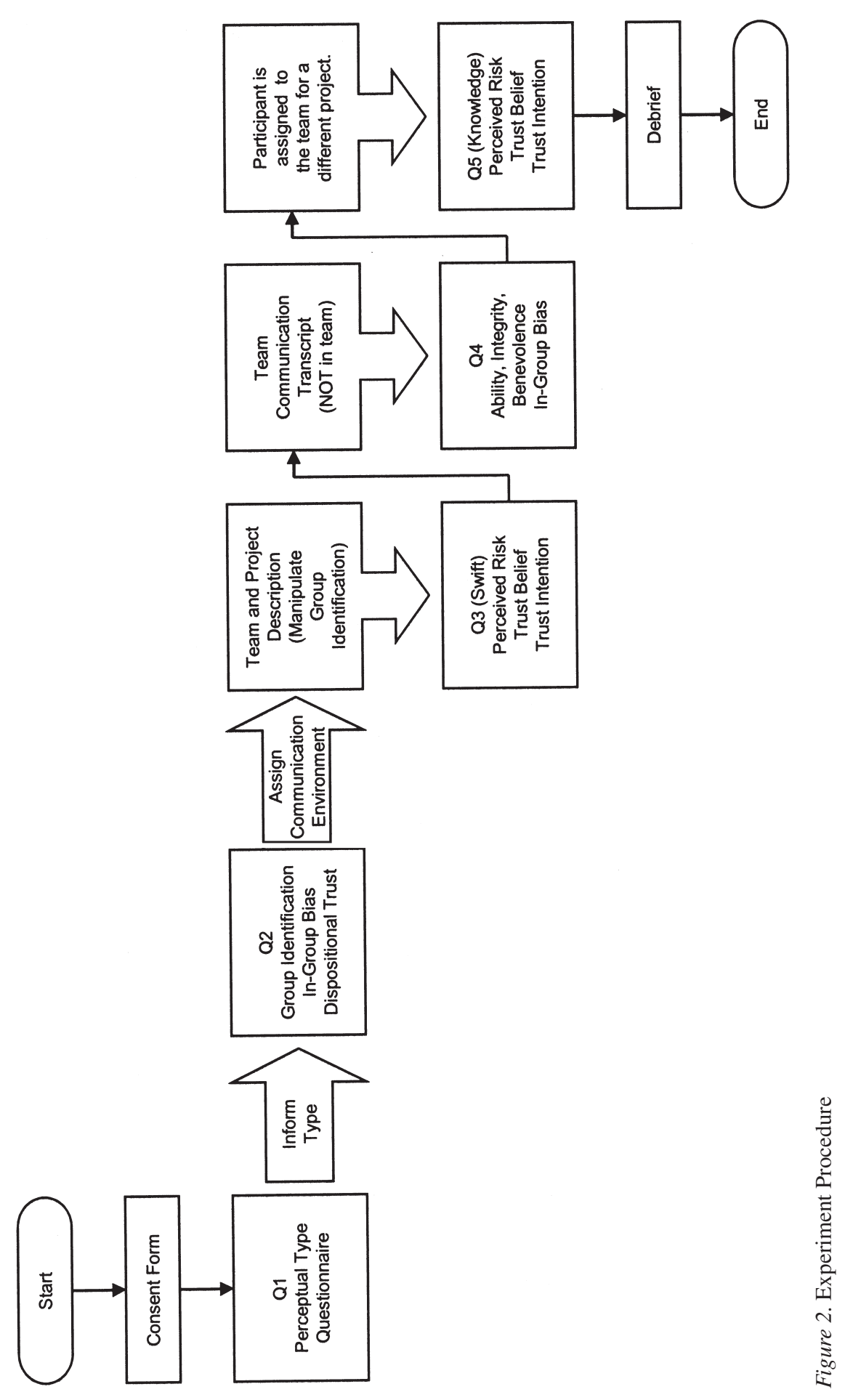


The experiment started by asking the participants to take a perceptual-style test. After the participants completed and submitted the test, they were informed that they were "grounding oriented" and were provided with explanations of the two orientations. They were then asked to fill out a second questionnaire measuring their disposition to trust and in-group bias.

The system then randomly assigned one of the two treatment vignettes (face-toface or e-mail) describing the backgrounds of the three characters, the nature of the project, and the communication environment. A third questionnaire was then used to measure their perceived risk, trust belief, and trust intention. At this point, participants had limited information about the three characters' personal characteristics and did not yet have any knowledge of each character's behavior. Trust belief measured at this point is swift trust.

Participants then read one of two transcripts depicting communications among the three characters. Afterward, the participants received a fourth questionnaire asking to assess each character's ability, integrity, benevolence, and in-group bias. The fifth questionnaire asked participants if they had to work with these individuals on a similar project using the same communication environment what would be their level of trust belief and trust intention toward each character and what level of risk would they associate with the situation. Trust belief measured at this point represents knowledge-based trust, given that the participants could base their trust judgments on their knowledge of each of the three characters' past behavior.

After they completed and submitted the fifth questionnaire, they were then debriefed, informed about the deception (i.e., the false perceptual test), and dismissed. The whole procedure took about 45 minutes to complete.

\section{Analysis and Results}

\section{Construct Validities and Reliabilities}

To VALIDATE THE MEASUREMENT MODEL, we first examined the construct reliabilities. The results, including item loadings and construct reliabilities, are summarized in Tables 1 and 2. Construct reliabilities are above the acceptable threshold of 0.70 , an indication of convergent validity [105].

Discriminant and convergent validity of the constructs was assessed twice. First, discriminant and convergent validity was assessed by using factor analysis. Following Chin [27], we assess the convergent and discriminant validity by checking for cross-loading. The results, including item loadings and construct reliabilities, are summarized in Tables 1 and 2. The results indicated that all items, except one, had loadings above the acceptable threshold of 0.70 [47]. Chin [27] provides two guidelines to help determine convergent and discriminant validity [84]. One, items should load higher on their corresponding constructs than on other constructs. Two, items should load higher on their corresponding constructs than any other items measuring other constructs. By examining Table 2, we can confirm that our measurement model 


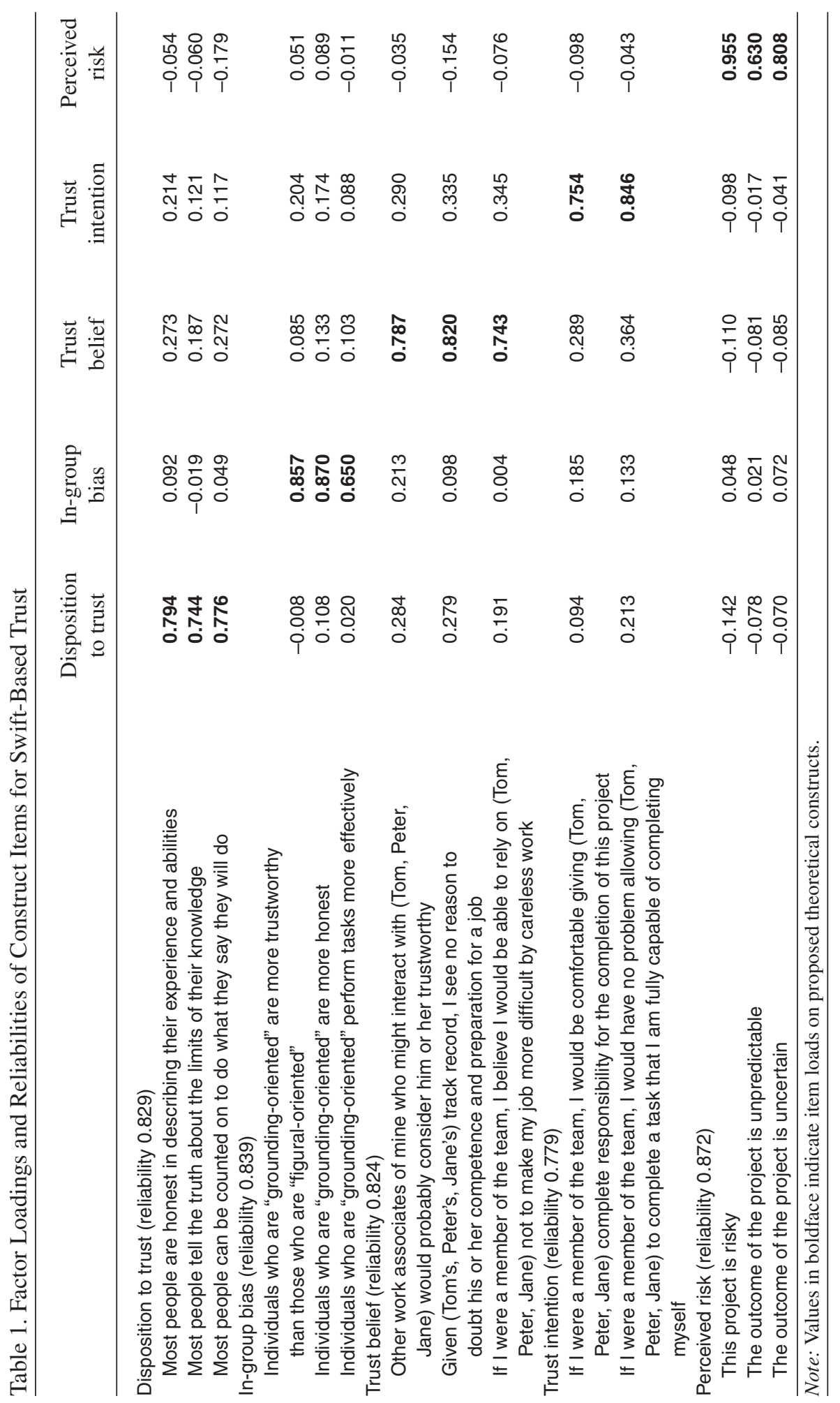




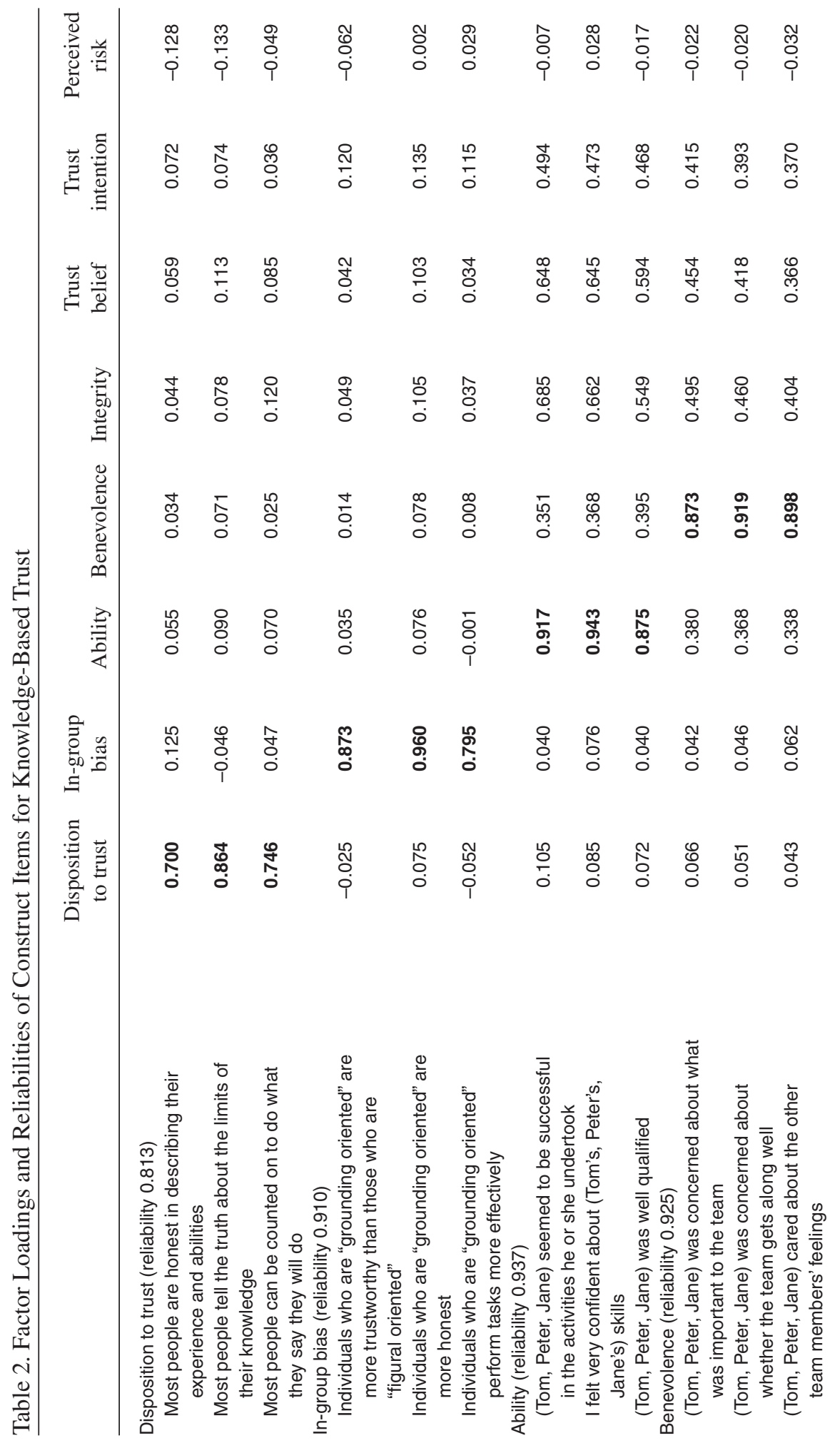




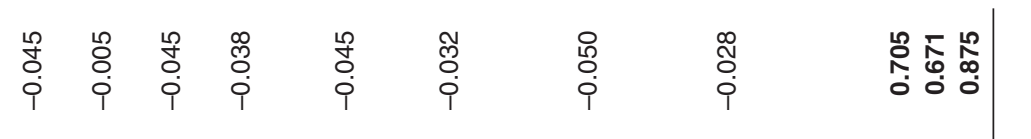

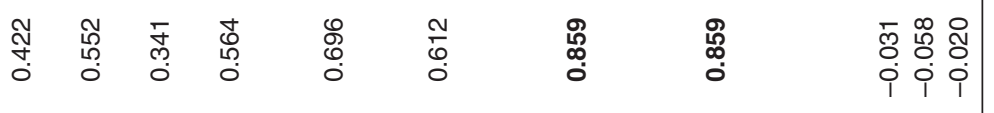

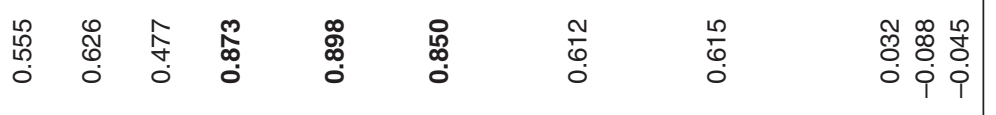

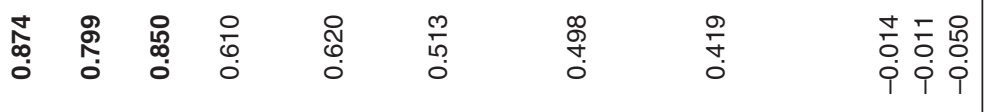

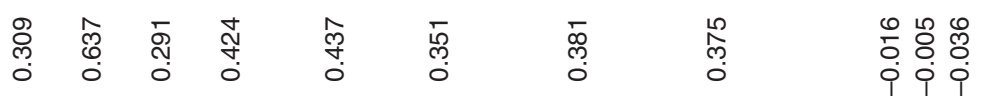

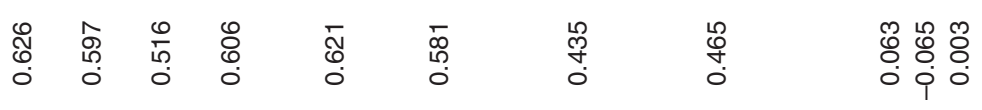

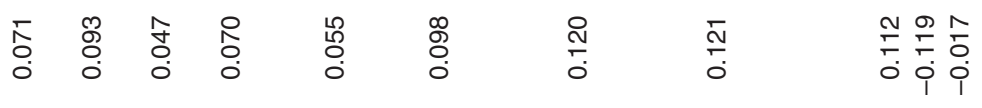

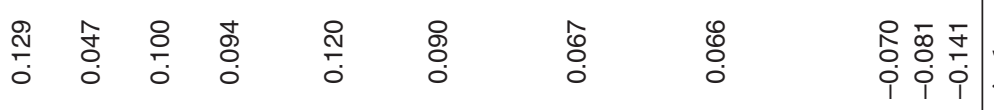

尊

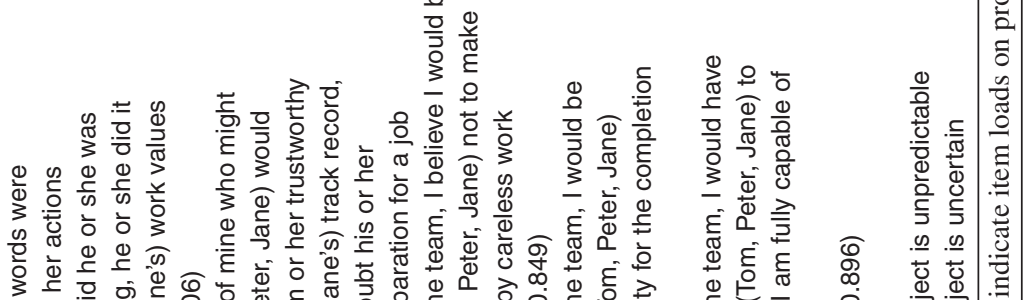

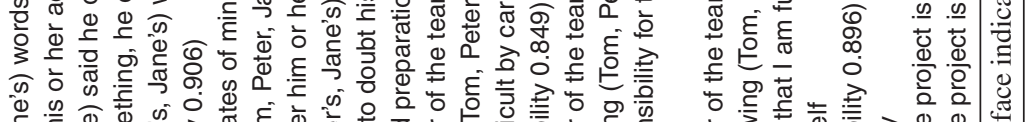

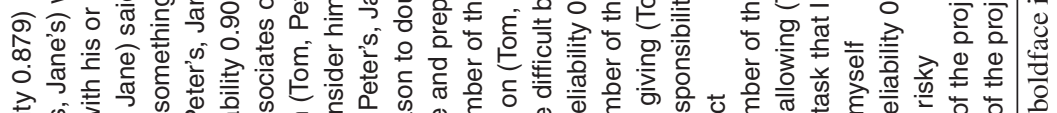
$\begin{array}{lllll} & \\ 0\end{array}$

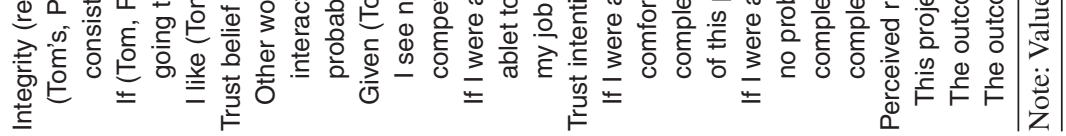


satisfies the two criteria suggested by Chin [27]. In addition, all items except one had loadings above the acceptable threshold of 0.70 [47]. Despite this, there does appear to be some cross-loading between ability and integrity and between trust belief and trust intention.

Second, discriminant and convergent validity was examined by determining if the items of a construct shared more variance internally than with any other constructs in the model [47]. The correlation matrices of the model of swift trust and of knowledgebased trust are shown in Tables 3 and 4, respectively. The average variance shared is indicated by average variance extracted (AVE), shown along the diagonals of a correlation matrix. In these tables, the AVE of each construct is larger than its corresponding row and column correlations, indicating adequate discriminant validity [47]. Overall, both tests taken together provide support for discriminant and convergent validity of our measure model.

\section{Manipulation Checks}

Two manipulation checks were performed: one to measure if the subjects were engaged in the task and the other to determine if the students actually perceived a difference between the two treatments: face-to-face and virtual communication environments. In order to ensure that participants were engaged in the study and that the vignettes did evoke a change in attitude, we conducted a manipulation check. We designed the vignettes so that Peter would be perceived as the highest in ability, Jane in integrity, and Tom in benevolence. A multivariate analysis of variance (MANOVA) found significant overall differences (Wilks's lambda $=81.396, p<0.001$ ) and follow-up analyses of variance (ANOVAs) found significant differences in ability $(F=46.70, p<0.001)$, integrity $(F=15.184, p<0.001)$, and benevolence $(F=23.65, p<0.001)$ among the characters. A post hoc Bonferroni test was performed for further analysis. Peter's ability was perceived to be higher than Jane's $(p<0.05)$ and Tom's $(p<0.05)$. Jane's integrity was perceived to be higher than Peter's $(p<0.10)$ and Tom's $(p<0.05)$. Tom's benevolence was perceived to be higher than Peter's $(p<0.05)$ and Jane's $(p<0.05)$. We conclude that the first manipulation was successful.

Another manipulation check was conducted to determine to what extent the subjects perceived a difference between the face-to-face treatment and the virtual treatment. Two paired $t$-tests were performed. The first compared the level of perceived risk between the face-to-face treatment and the virtual treatment in the swift trust model. The results indicated that subjects did perceive higher levels of risk in the virtual treatment $($ mean $=3.43)$ than the face-to-face treatment $($ mean $=2.69), t($ degrees of freedom $[\mathrm{df}]=100)=5.30, p<0.001$. The second compared the level of perceived risk between the face-to-face treatment and the virtual treatment in the knowledge-based trust model. The results indicated that subjects perceived higher levels of risk in the virtual treatment $($ mean $=4.17)$ group than the face-to-face treatment $($ mean $=3.75)$, $t(\mathrm{df}=100)=2.91, p=0.004$. Both tests indicate that the manipulation of the communication media was successful. 


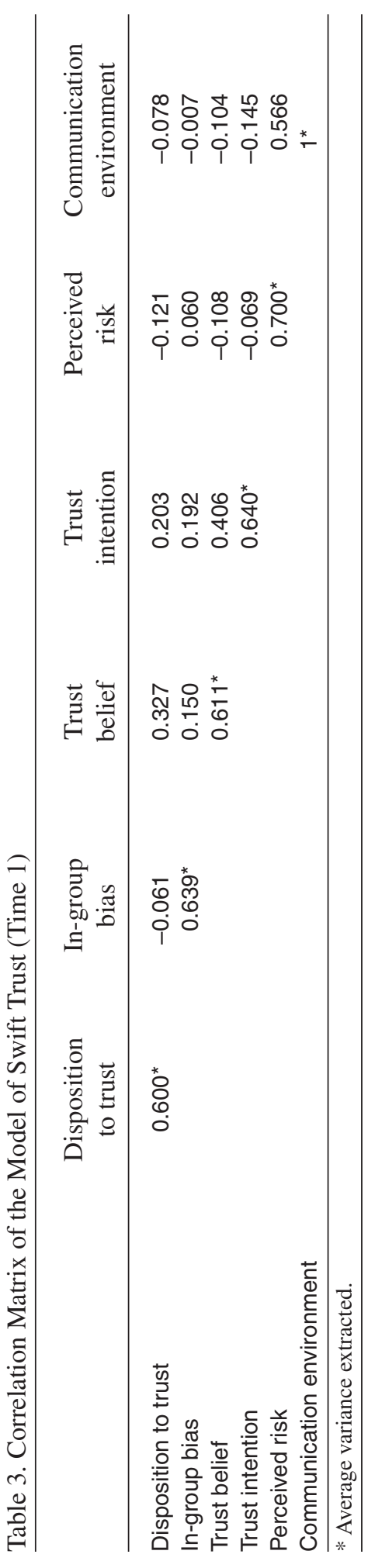




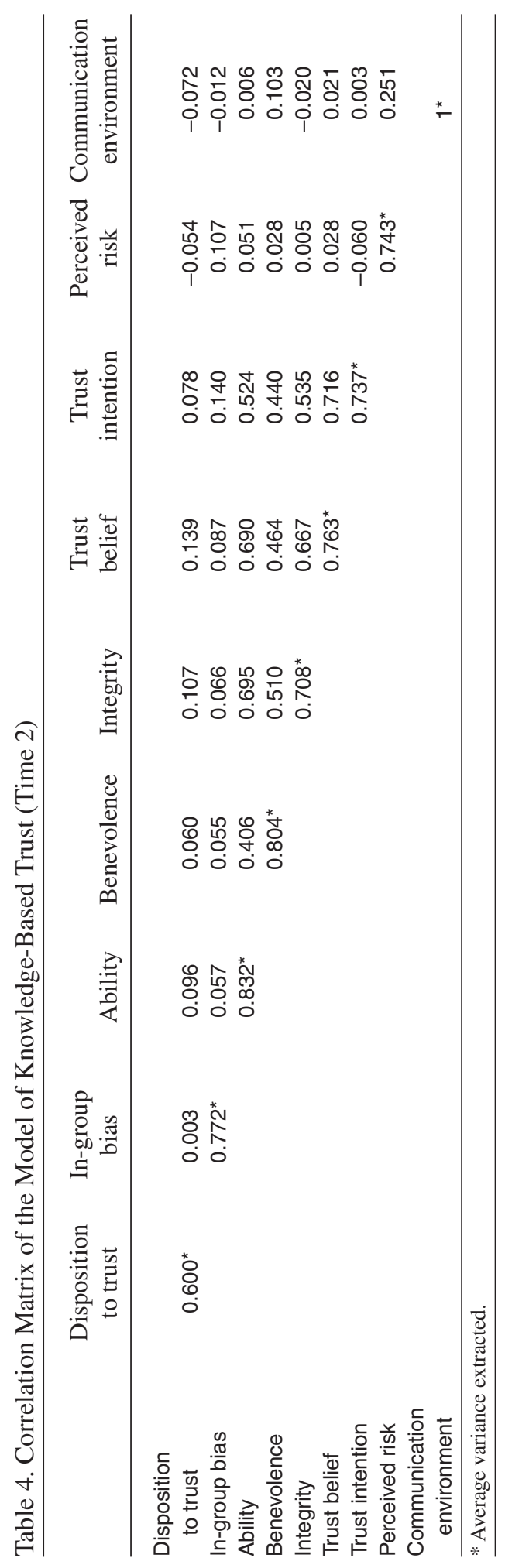




\section{Common Method Variance}

Data collected at the same time using survey research has the potential to suffer from common method variance (CMV). We conducted Harman's single-factor test to fully investigate the possibility of CMV. We ran an exploratory factor analysis [91, 118]. CMV is said to exist if the first factor accounts "for the majority" of the variance in the variables [117, p. 536]. The first factor explained 23 percent of the variance in the swift trust model, and 31 percent of the variance in the knowledge-based model. Since both are less than 50 percent, we conclude that common method variance was not a major issue.

\section{Hypothesis Testing}

The proposed model was tested using PLS using PLS Graph 3.00. Two separate models were built: the model for swift trust was tested using the data collected before the participants received the communication transcripts, and the model for knowledge-based trust was tested using the data collected after they had read the transcripts. Subjects rated each character (Tom, Peter, and Jane) separately. The data was input into PLS as separate data points, not an average. In other words, we treated each response for every subject as a separate sample case. This would be problematic with ordinary least squares (OLS) regression, because this violates the assumption that the cases have to be independent [103]. However, with PLS, "no assumptions are made regarding the joint distribution of the indicators or the independence of sample cases" [27, p. 332]. As a result, this approach is appropriate when using PLS [125].

\section{Swift Trust}

Figure 3 presents the results of the swift trust model. $\mathrm{H} 1$ and $\mathrm{H} 2$, which hypothesized that one's deposition to trust and in-group bias would increase an individual's swift trust belief (respectively) were both supported: disposition to trust $(\beta=0.317, p<0.001$ ) had a positive effect on trust belief as did in-group bias $(\beta=0.132, p<0.01)$. H6a, which argued that the use of an ICT environment would increase perceived risk, was supported $(\beta=0.566, p<0.001)$. H5a, which argued that the difference between trust belief and perceived risk would influence trust intention, was also supported ( $\beta=0.372$, $p<0.001)$. As an aside, we note that the control variables had small but significant effects on trust belief and trust intention.

\section{Knowledge-Based Trust}

Figure 4 presents the results of the knowledge-based trust model. H3a, H3b, and H3c, which argued that perceptions of an individual's ability, integrity, and benevolence would influence an individual's knowledge-based trust belief (respectively), were all supported: ability $(\beta=0.422, p<0.001)$, integrity $(\beta=0.298, p<0.001)$, and benevolence $(\beta=0.138, p<0.001)$ were all significant. $\mathrm{H} 4 \mathrm{a}$ and $\mathrm{H} 4 \mathrm{~b}$, which hypothesized 


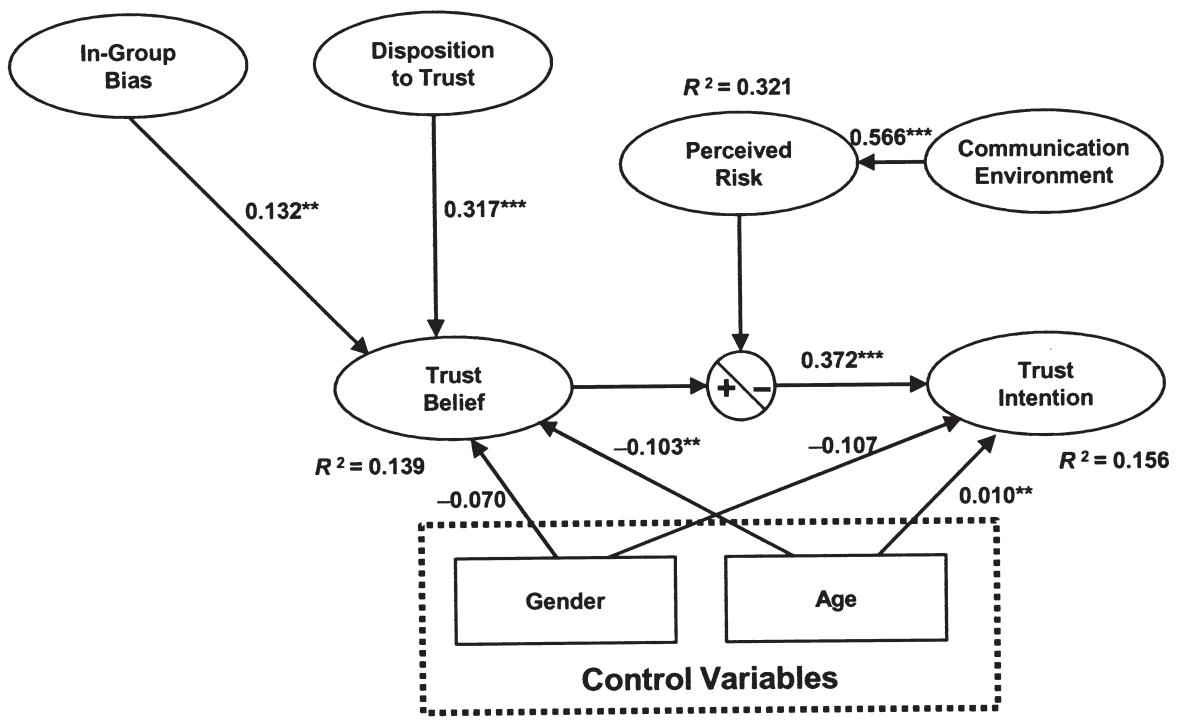

Figure 3. Swift Trust

** Significant at the 0.01 level; *** significant at the 0.001 level.

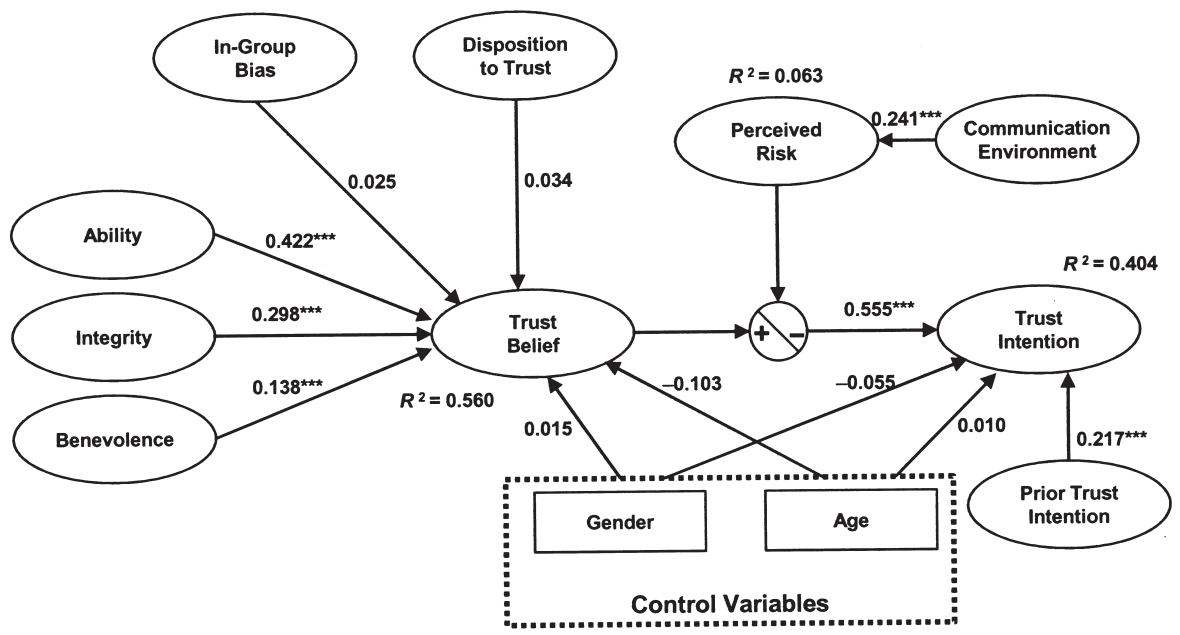

Figure 4. Knowledge-Based Trust *** Significant at the 0.001 level.

that one's disposition to trust and in-group bias would not affect knowledge-based trust, were both supported: disposition to trust $(\beta=0.034, p=$ not significant [n.s.]) and in-group bias $(\beta=0.025, p=$ n.s.). H6b, which argued that the use of an ICT environment would increase perceived risk, was supported $(\beta=0.251, p<0.001)$. $\mathrm{H} 5 \mathrm{~b}$, which argued that the difference between trust belief and perceived risk would influence trust intention, was supported $(\beta=0.555, p<0.001)$. H7, which argued that 
an individual's initial swift judgments would continue to influence knowledge-based trust intentions, was also supported $(\beta=0.217, p<0.001)$. The control variables were not significant.

\section{Discussion}

WE FOUND THAT, INITIALLY, INDIVIDUALS USED category-based information processing and their own disposition to trust to form an initial swift trust judgment. Once individuals acquired some information about each team member's behavior, they used this knowledge about his or her ability, integrity, and benevolence to form a knowledge-based trust judgment. The impact of the individual's own initial swift trust judgment also played a significant role in knowledge-based trust formation. Thus, after individuals gained some knowledge of team members' behaviors, they no longer relied on their own disposition to trust or category-based processing to form trust, but instead viewed each team member as an individual and used that individual's past behavior to assess trust - but their own initial swift judgments colored their subsequent knowledge-based trust judgments. We also found that the use of an ICT-mediated communication environment increased participants' perceived risk and therefore, ceteris paribus, decreased their intention to trust.

\section{Swift Trust}

Both disposition to trust and in-group bias (resulting from group identification) were found to influence trust belief when individuals did not have any knowledge of team member's behavior. Disposition to trust had greater influence on the formation of swift trust $(\beta=0.317, p<0.001)$ than did in-group bias $(\beta=0.132, p<0.05)$. This implies that individuals tend to rely more on their general tendency, formed through numerous past trust experiences, than on this type of group categorization in forming their trust judgments.

It is also interesting to note that an individual's in-group identification and bias can be easily influenced. In this study, participants showed significant group identification and bias based on an artificial—and false-categorization. If an artificial manipulation can have such a strong impact on how individuals process categorical information, the influence of real social categories such as race, gender, occupation, and so forth may have much stronger effects on swift trust.

\section{Knowledge-Based Trust}

The results suggest that when relevant information about behaviors was present, individuals used it instead of the categorical bases of swift trust. Knowledge-based trust was strongly influenced by the individuals' ability, benevolence, and integrity. The quickly diminished influence of depersonalized categories on trust only further suggests the fragility of swift trust. In order to make more accurate judgments, individuals put 
aside the depersonalized categories and choose to focus on the behaviors of individuals when that information is accessible. Knowledge-based trust $\left(R^{2}=0.560\right)$ explained more of the variance in trust intention than did swift trust $\left(R^{2}=0.159\right)$, implying that trust formed through deliberate cognitive assessment can be stronger and "thicker" and can lead individuals to engage in greater trusting behavior [83, 98, 99].

Among the three antecedents of knowledge-based trust, ability and integrity showed the greatest influence on knowledge-based trust $(\beta=0.422, p<0.001$ for ability; $\beta=0.298, p<0.001$ for integrity; $\beta=0.138, p<0.001$ for benevolence). This is consistent with results from previous studies $[4,63]$ and supports the argument that members of a task-focused temporary team consider benevolence to be less important to short-term performance than ability or integrity [99].

The factors influencing swift trust (disposition to trust and in-group bias) did not significantly influence knowledge-based trust. However, the prior trusting intention from the swift trust model had a significant effect on the subsequent knowledge-based trust intention. This suggests that prior swift trust judgments may have anchored or biased subsequent processing of information about others' behaviors. The interpretation of an outcome of a trust transaction can be influenced by an individual's prior trust judgments. People have a tendency to focus on information that supports their initial judgments and discount information that opposes them [150]. This indicates that even when the antecedents of swift trust become insignificant in later trust judgments, their "residual" effects continue to influence knowledge-based trust intentions.

\section{Communication Environment and Risk Assessment}

Communication environment had a significant effect on the level of risk perceived. Individuals considered communication in an ICT-mediated environment to be inherently more risky than face-to-face communication. This influence was significant both before and after information about team members' behaviors was available. The low variance explained in perceived risk $\left(R^{2}=0.321\right.$ and 0.063$)$ suggests that communication environment is only one of many possible situational factors that may influence the level of risk perceived. The lower $R^{2}$ of perceived risk in the knowledge-based trust model (0.063) implies that once participants gained even a modest personal knowledge of others' behaviors, the uncertainties introduced by the geographic distance and the use of ICTs had less impact on perceived risk; in other words, once participants gained knowledge of others' behaviors, they were less likely to perceive geographic separation and the dependence of ICTs as an influential source of risk.

\section{Limitations}

Vignettes have been used extensively throughout the social science fields since the 1950s [50]; nonetheless, their use is not unproblematic [51]. Limitations related to the use of vignettes should be noted. In particular, subjects in vignette-based studies such as this one are not responding to the interaction and feedback of other individuals but 
to a "hypothetical scenario" [57]. In this study, subjects did not actually use the communication media and were not members of an actual team. As a result, vignettes can suffer from two problems. First, vignettes are sometimes not as powerful a manipulation as traditional experiential experiments and may result in nonsignificant findings [51]. However, based on the results (and our manipulation checks), it would appear that our study did not suffer from this problem.

Second, subjects could potentially respond differently to a hypothetical scenario than they would in a real scenario. This is a common limitation of all experimental research, including those not using vignettes. A recent meta-analysis revealed that the correlation between explanations and reactions to decision making in studies that used vignettes were 0.34 versus 0.33 for nonvignette studies [133]. In other words, the meta-analysis found a similar relationship between these variables in studies employing vignettes and nonvignette studies. Results in other studies found similar comparisons [36, 123]. This provides some support that when individuals are presented with vignettes, they respond as they do in a real scenario. Nonetheless, "like any research tool vignettes can never mirror completely the reality and dynamism of people's lives" [58, p. 383]. In addition, it should be noted that although the measurement model met sufficient criteria for convergent and divergent validity [27], there were several cross-loadings that may limit the findings of the study.

\section{Implications for Future Research}

This study provides empirical evidence that the factors that influence trust formation change over time as individuals gain experience with the behavior of team members. As a result of this dynamic nature of trust formation, we propose that swift trust and history-dependent knowledge-based trust are two forms of trust manifested at different stages of a relationship. Much research has been done on knowledge-based trust. Given that swift trust judgments based solely on team member characteristics linger on and influence trust judgments made after individuals have knowledge of others' behaviors, we believe that more research is needed on swift trust and the factors that influence initial trust judgments before knowledge of behaviors has been gained.

It should also be noted that the control variables (gender and age) were significant predictors of trust and trust intention in the swift trust model but not in the knowledgebased model. This supports prior literature that suggests that gender and age can act as initial cues that individuals use to assess trust in the absence of knowledge about the trustee [106]. However, once individuals have sufficient knowledge to assess trust on past behavior, gender and age become insignificant. Future research may examine the role of team diversity and trust in greater detail.

Future studies may examine the impact of group bias in greater depth. Understanding how group bias and negative stereotypes influence the relational (trust, identity, obligations, and norms) development in virtual teams would significantly contribute to our understanding. Sensitive issues relating to team diversity (such as age, gender, and race) and social stigmas [111] could all benefit from the use of vignettes in the IS literature. 
Future research should also focus on the factors that act to shift the basis of trust from swift trust to knowledge-based trust. How much knowledge of others' behaviors is needed to trigger the shift from swift trust to cognitive trust? Given the difficulty in assessing other team members through solely ICT-mediated communication, does the point at which the bases of trust shift from swift trust to knowledge-based trust occur later in virtual teams? What are the implications of such a later shift to the management of virtual teams? What mechanisms can aid in this transition?

We also found that an ICT-mediated communication environment increased perceived risk. Given that collaboration and communication through the use of ICTs has become common, research focusing on the design and use of various ICTs for enhancing trust development and reducing perceived risk becomes important [49]. Future studies are needed to answer questions such as how different ICT characteristics, individually or combined, may influence perceptions of risk at different stages of collaboration. As individuals shift bases of trust formation, what behaviors involving the use of ICT may promote or inhibit the development and reduction of risk?

Future studies should manipulate the frequency, length, and nature (small talk, discussions of the project, etc.) of the interactions between the team members that lead to the development of knowledge-based trust. Individuals might perceive others differently depending on the nature of interactions between the team members. In addition, prior theory would suggest that communication media differs in its ability to facilitate understanding by constraining or enabling the processing of information [124]. As a result, future studies should examine the impact of several types of communication media on the development of trust within teams.

Finally, we hope that this research spurs an increase in the use of vignettes in information systems research. Vignettes offer several advantages (as well as limitations) to the researcher, the most important being the very precise control they bring. By using vignettes, researchers can be assured that each experimental participant is presented with exactly the same stimulus, something that is not possible with the use of experimental teams whose members interact directly.

For example, the use of vignettes may be a useful tool in addressing the recent calls for considering the "distinction between trust and trustworthiness and the distinct dimensions of trustworthiness" and to study the "distinction between trusting beliefs . . and trusting intentions" [49, p. 277]. As pointed out in Gefen et al. [49], making the "separation statistically is hard" but we believe the use of vignettes will allow researchers to manipulate and standardize the behavior exposed to all subjects. This will enable researchers "to tease out some subtle issues in terms of how trust operates" [49, p. 277]. This would be difficult to accomplish in a field setting or a traditional lab experiment where participants can interact in unexpected ways.

\section{Implications for Practice}

Trust formation is a dynamic process that takes different forms at different stages of a relationship. Therefore, the strategies for managing trust need to incorporate this dynamic aspect of trust. At the initial stages of a work relationship, trust is formed 
presumptively based on simple category-based information processing of individual characteristics because there is insufficient knowledge of individual behaviors. Hence, managerial emphasis should be placed on promoting group identification. At later stages of a work relationship, the knowledge of team member's past behavior plays a critical role in determining trust. Thus, the ability, integrity, and benevolence of individual team members should be emphasized, and managerial emphasis should be on providing individuals opportunities for personal interaction to allow team members to better understand each other.

The results from this study demonstrate that swift trust has a strong influence on an individual's initial trust formation and on subsequent knowledge-based trust intention. In short, it is not just that first impressions matter, but that information obtained about other team members before the first impression matters. This information not only affects initial swift trust, but swift trust judgments linger on, coloring the perceptions of subsequent behavior. As a result, some team members will find it much more difficult to gain the trust of other team members simply because the categorical variables used in that initial swift trust judgment were not good predictors of trust, yet that initial swift trust judgment influenced subsequent judgments.

Past research has indicated that teams with high levels of swift trust outperform teams that exhibit low levels of swift trust $[61,67,153]$. Although swift trust is fragile and temporary, managers should still incorporate strategies to enhance swift trust in initial interactions. In addition, mechanisms that promote a sense of group identification should be encouraged. And, since swift trust judgments influence knowledgebased trust, managers should act upon swift trust and encourage interactions between individuals for gathering personal information that contributes to the formation of knowledge-based trust.

The simple perception of communication through an ICT-mediated environment (not the actual use) was shown to have an adverse effect on trust by increasing the level of perceived risk. This raises two issues that managers of teams using ICT as their main communication channel should consider. First, with ICT-mediated communication, individuals have fewer opportunities to engage in more traditional, face-to-face trustbuilding activities. Thus, team support mechanisms such as team-building exercises may be utilized to reduce negative biases and stereotypical attributions by providing chances for individuals to build relationships and accumulate personal knowledge of each other. Such exercises may also speed up the transition from swift trust to knowledge-based trust. Second, well-established rules for using ICT media could increase the level of perceived control $[61,114]$ and, in turn, reduce the level of perceived risk. Frequent and regular communications that encourage the sharing of task outputs will also facilitate the development and maintenance of trust in ICT-mediated communication environments $[61,63]$.

\section{Conclusion}

HISTORY-DEPENDENT KNOWLEDGE-BASED TRUST and swift trust appear to represent two contradictory views of trust formation. However, they represent two different processes 
by which trust is formed at different stages of a relationship. The results of this study indicate that category-based processing and disposition to trust dominate the initial formation of swift trust. Once individuals accumulate sufficient information of others' behaviors to assess their trustworthiness, the effects of swift trust decline and knowledge-based trust based on perceived ability, integrity, and benevolence becomes dominant-yet the impact of initial swift judgments (often inaccurate) linger on and continue to influence knowledge-based trust judgments.

Acknowledgment: The authors thank all of the participants of the Indiana University Information Systems Workshop for their helpful comments on an earlier draft of this paper.

\section{REFERENCES}

1. Abrams, D.; Wetherell, M.; Cochrane, S.; Hogg, M.A.; and Turner, J.C. Knowing what to think by knowing who you are: Self-categorization and the nature of norm formation, conformity and group polarization. British Journal of Social Psychology, 29, 2 (1990), 97-119.

2. Alge, B.J.; Wiethoff, C.; and Klein, H.J. When does the medium matter? Knowledgebuilding experiences and opportunities in decision-making teams. Organizational Behavior and Human Decision Processes, 91, 1 (2003), 26-37.

3. Amabile, T.M.; Patterson, C.; Mueller, J.; Wojcik, T.; Odomirok, P.W.; Marsh, M.; and Kramer, S. Academic-practitioner collaboration in management research: A case of crossprofession collaboration. Academy of Management Journal, 44, 2 (2001) 418-431.

4. Aubert, B., and Kelsey, B. Further understanding of trust and performance in virtual teams. Small Group Research, 34, 5 (2003), 575-618.

5. Baard, P.P.; Deci, E.L.; and Ryan, R.M. Intrinsic need satisfaction: A motivational basis of performance and well-being in two work settings. Journal of Applied Social Psychology, 34, 10 (2004), 2045-2068.

6. Barber, B. The Logic and Limits of Trust. New Brunswick, NJ: Rutgers University Press, 1983.

7. Bhattacherjee, A. Individual trust in online firms: Scale development and initial test. Journal of Management Information Systems, 19, 1 (Summer 2002), 211-241.

8. Bettencourt, B.A.; Dorr, N.; Charlton, K.; and Hume, D.L. Status differences and in-group bias: A meta-analytic examination of the effects of status stability, status legitimacy, and group permeability. Psychological Bulletin, 127, 4 (2001), 520-542.

9. Bews, N.F., and Rossouw, G.J. A role for business ethics in facilitating trustworthiness. Journal of Business Ethics, 39, 4 (2002), 377-390.

10. Bhattacharya, R.; Devinney, T.M.; and Pillutla, M.M. A formal model of trust based on outcomes. Academy of Management Review, 23, 3 (1998), 459-472.

11. Bierman, H., Jr.; Bonini, C.P.; and Hausman, W.H. Quantitative Analysis for Business Decisions, 3d ed. Homewood, IL: Irwin, 1969.

12. Boyle, R., and Bonacich, P. The development of trust and mistrust in mixed-motive games. Sociometry, 33, 2 (1970), 123-139.

13. Bradach, J.L., and Eccles, R.G. Price, authority, and trust—From ideal types to plural forms. Annual Review of Sociology, 15, 1 (1989), 97-118.

14. Brewer, M.B. In-group bias in the minimal intergroup situation: A cognitive-motivational analysis. Psychological Bulletin, 86, 2 (1979), 307-324.

15. Brewer, M.B. Ethnocentrism and its role in interpersonal trust. In M.B. Brewer and B.E. Collins (eds.), Scientific Inquiry and the Social Sciences. San Francisco: Jossey-Bass, 1981, pp. 214-231.

16. Brewer, M.B., and Silver, M. In-group bias as a function of task characteristics. European Journal of Social Psychology, 8, 3 (1978), 393-400.

17. Brown, R.; Condor, S.; Matthews, A.; Wade, G.; and Williams, J. Explaining intergroup differentiation in an industrial organization. Journal of Occupational Psychology, 59, 4 (1986), 273-286. 
18. Burke, K., and Chidambaram, L. Developmental differences between distributed and faceto-face groups in electronically supported meeting environments-An exploratory investigation. Group Decision and Negotiation, 4, 3 (1995), 213-233.

19. Burt, R.S., and Knez, M. Kinds of third-party effects on trust. Rationality and Society, 7, 3 (1995), 255-292.

20. Buskens, V., and Raub, W. Embedded trust: Control and learning. In E. Lawler and S. Thye (eds.), Advances in Group Processes. Amsterdam: JAI/Elsevier, 2002, pp. 167-202.

21. Cascio, W. Managing a virtual workplace. Academy of Management Executive, 14, 3 (2000), 81-90.

22. Castelfranchi, C., and Tan, Y. The role of trust and deception in virtual societies. International Journal of Electronic Commerce, 6, 2 (2002), 55-70.

23. Chaiken, S., and Maheswaran, D. Heuristic processing can bias systematic processing: Effects of source credibility, argument ambiguity and task importance on attitude judgment. Journal of Personality and Social Psychology, 66, 3 (1994), 460-473.

24. Chaiken, S.; Duckworth, K.L.; and Darke, P. When parsimony fails. . . Psychological Inquiry, 10, 2 (1999), 118-123.

25. Chen, S., and Chaiken, S. The heuristic semantic model in its broader context. In S. Chaiken and Y. Trope (eds.), Dual-Process Theories in Social and Cognitive Psychology. New York: Guilford, 1999, pp. 73-96.

26. Chidambaram, L. Relational development in computer-supported groups. MIS Quarterly, 20, 2 (1996), 143-165.

27. Chin, W.W. The partial least squares approach for structural equation modeling. In G.A. Marcoulides (ed.), Modern Methods for Business Research. Hillsdale, NJ: Lawrence Erlbaum, 1998, pp. 295-336.

28. Colquitt, J.A., and Jackson, C.L. Justice in teams: The context-sensitivity of justice rules across individual and team contexts. Journal of Applied Social Psychology, 36, 4 (2006), 870-901.

29. Coppola, N.W.; Hiltz, S.R.; and Rotter, N. Building trust in virtual teams. IEEE Transactions on Professional Communication, 47, 2 (2004), 95-104.

30. Couger, J.D. Preparing IS students to deal with ethical issues. MIS Quarterly, 13, 2 (1989), 211-218.

31. Cramton, C.D. The mutual knowledge problem and its consequences for dispersed collaboration. Organization Science, 12, 3 (2001), 346-371.

32. Cyr, D. Modeling Web site design across cultures: Relationships to trust, satisfaction, and e-loyalty. Journal of Management Information Systems, 24, 4 (Spring 2008), 47-72.

33. Daft, R.L.; Lengel, R.H.; and Trevino, L. Message equivocality, media selection, and manager performance. MIS Quarterly, 11, 3 (1987), 355-366.

34. Das, T.K., and Teng, B. Trust, control, and risk in strategic alliances: An integrated framework. Organization Studies, 22, 2 (2001), 251-283.

35. Davenport, T.H., and Prusak, L. Working Knowledge: How Organizations Manage What They Know. Boston: Harvard Business School Press, 1998.

36. DeCremer, D.; Van Dijke, M.; and Bos, A.E.R. When leaders are seen as transformational: The effects of organizational justice. Journal of Applied Social Psychology, 37, 8 (2007), $1797-1816$.

37. Dion, K.L. Cohesiveness as a determinant of ingroup-outgroup bias. Journal of Personality and Social Psychology, 28, 2 (1973), 163-171.

38. Dirks, K.T., and Ferrin, D.L. Trust in leadership: Meta-analytic findings and implications for research and practice. Journal of Applied Psychology, 87, 4 (2002), 611-628.

39. Dubé, L., and Paré, G. Global virtual teams. Communications of the ACM, 44, 12 (2001), $71-73$.

40. Elasbach, K.D., and Elofson, G. How the "packaging" of decision explanations affects perceptions of trustworthiness. Academy of Management Journal, 43, 1 (2000), 80-89.

41. El-Shinnawy, M., and Markus, M. Media richness theory and new electronic communication media: A study of voice mail and electronic mail. In J.I. DeGross, J.D. Becker, and J.J. Elam (eds.), Proceedings of the Thirteenth International Conference on Information Systems. Atlanta: AIS, 1992, pp. 91-105.

42. Escher, M.C. The Graphic Work. Cologne: Benedikt Taschen-Verlag, 1992. 
43. Fine, G.A., and Holyfield, L. Secrecy, trust, and dangerous leisure: Generating group cohesion in voluntary organizations. Social Psychology Quarterly, 59, 11 (1996), 22-38.

44. Fiske, S.T., and Taylor, S.F. Social Cognition, 2d ed. New York: McGraw-Hill, 1991.

45. Fiske, S.T.; Lin, M.; and Neuberg, S.L. The continuum model: Ten years later. In S. Chaiken and Y. Trope (eds.), Dual-Process Theories in Social and Cognitive Psychology. New York: Guilford Press, 1999, pp. 231-254.

46. Flaskerud, J.H. Use of vignettes to elicit responses toward broad concepts. Nursing Research, 28, 2 (1979), 210-212.

47. Fornell, C., and Larcker, D.F. Evaluating structural equations models with unobservable variables and measurement error. Journal of Marketing Research, 18, 1 (1981), 39-50.

48. Gattiker, U.E., and Kelley, H. Morality and computers: Attitudes and differences in moral judgments. Information Systems Research, 10, 3 (1999), 233-254.

49. Gefen, D.; Benbasat, I.; and Pavlou, P.A. A research agenda for trust in online environments. Journal of Management Information Systems, 24, 4 (Spring 2008), 275-286.

50. Gould, D. Using vignettes to collect data for nursing research studies: How valid are the findings? Journal of Clinical Nursing, 5, 4 (1996), 207-212.

51. Greenberg, J., and Eskew, D.E. The role of role playing in organizational research. Journal of Management, 19, 2 (1993), 221-241.

52. Gurtman, M.B. Trust, distrust, and interpersonal problems: A circumplex analysis. Journal of Personal Sociology Psychology, 62, 6 (1992), 989-1002.

53. Handy, C. Trust and virtual organization. Harvard Business Review, 73, 3 (1995), $40-50$.

54. Harrington, S.J. The effect of codes of ethics and personal denial of responsibility on computer abuse judgments and intentions. MIS Quarterly, 20, 3 (1996), 257-278.

55. Hastorf, A.H., and Cantril, H. They saw a game: A case study. Journal of Abnormal and Social Psychology, 49, 1 (1954), 129-134.

56. Hewstone, M.; Rubin, M.; and Willis, H. Intergroup bias. Annual Review of Psychology, 53, 1 (2002), 575-604.

57. Hughes, R. Considering the vignette technique and its application to a study of drug injecting and HIV risk and safer behavior. Sociology of Health and Illness, 20, 3 (1998), 381-400.

58. Hughes, R., and Huby, M. The application of vignettes in social and nursing research. Journal of Advanced Nursing, 37, 4 (2002), 382-386.

59. Hughes, R.; Rosenbach, W.; and Clover, W. Team development in an intact, ongoing work group: A quasi-field experiment. Group and Organization Studies, 8, 2 (1983), 161-186.

60. Ichijo, K.; von Krogh, G.; and Nonaka, I. Knowledge enablers. In G. von Krogh, J. Roos, and D. Kleine (eds.), Knowing in Firms: Understanding, Managing and Measuring Knowledge. London: Sage, 2000, pp. 173-203.

61. Jarvenpaa, S.L., and Leidner, D.E. Communication and trust in global virtual teams. Organization Science, 10, 6 (1999), 791-815.

62. Jarvenpaa, S.L., and Staples, D.S. The use of collaborative electronic media for information sharing: An exploratory study of determinants. Journal of Strategic Information Systems, 9, 2-3 (2000), 129-154.

63. Jarvenpaa, S.L.; Knoll K.; and Leidner D.E. Is anybody out there? The implications of trust in global virtual teams. Journal of Management Information Systems, 14, 4 (Spring 1998), 29-64.

64. Jarvenpaa, S.L.; Shaw, T.R.; and Staples, S.D. Toward contextualized theories of trust: The role of trust in global virtual teams. Information Systems Research, 15, 3 (2004), 250-267.

65. Jeanquart-Barone, J. Trust differences between supervisors and subordinates: Examining the role of race and gender. Sex Roles, 29, 1-2 (1993), 1-11.

66. Jiang, J.J.; Klein, G.; and Carr, C.L. Measuring information system service quality: SERVQUAL from the other side. MIS Quarterly, 26, 2 (2002), 145-166.

67. Kanawattanachai, P., and Yoo, Y. Dynamic nature of trust in virtual teams. Journal of Strategic Information Systems, 11, 3-4 (2002), 187-213.

68. Keil, M.; Depledge, G.; and Rai, A. Escalation: The role of problem recognition and cognitive bias. Decision Sciences, 38, 3 (2007), 391-421.

69. Kiesler, S., and Cummings, J. What do we know about proximity and distance in work groups? A legacy of research. In P. Hinds and S. Kiesler (eds.), Distributed Work. Cambridge, MA: MIT Press, 2002, pp. 57-82. 
70. Kim, D.J. Self-perception-based versus transference-based trust determinants in computermediated transactions: A cross-cultural comparison study. Journal of Management Information Systems, 24, 4 (Spring 2008), 13-45.

71. Klimoski, R.J., and Karol, B.L. The impact of trust on creative problem solving groups. Journal of Applied Psychology, 61, 5 (1976), 630-633.

72. Komiak, S.Y.X., and Benbasat, I. Understanding customer trust in agent-mediated electronic commerce, Web-mediated electronic commerce, and traditional commerce. Information Technology and Management, 5, 1-2 (2004), 181-207.

73. Komiak, S.Y.X., and Benbasat, I. The effects of internalization and familiarity on trust and adoption of recommendation agents. MIS Quarterly, 30, 4 (2006), 941-960.

74. Komiak, S.Y.X.; Wang, W.; and Benbasat, I. Trust building in virtual salespersons versus in human salespersons: Similarities and differences. e-Service Journal, 3, 3 (Summer 2005), 49-63.

75. Kramer, R.M. Trust and distrust in organizations: Emerging perspectives, enduring questions. Annual Review Psychology, 50, 1 (1999), 569-598.

76. Kramer, R.M., and Goldman, L. Helping the group or helping yourself? Social motives and group identity in resource dilemmas. In D.A. Schroeder (ed.), Social Dilemmas. Westport, CT: Praeger, 1995, pp. 49-67.

77. Kramer, R.M., and Tyler, T.R. (eds.). Trust in Organizations: Frontiers of Theory and Research. Thousand Oaks, CA: Sage, 1996.

78. Kramer, R.M.; Brewer, M.; and Hanna, B. Collective trust and collective action: The decision to trust as a social decision. In R.M. Kramer and T.R. Tyler (eds.), Trust in Organizations: Frontiers of Theory and Research. Thousand Oaks, CA: Sage, 1996, pp. 90-113.

79. Lanza, M.L., and Carifio, J. Use of a panel of experts to establish validity for patient assault vignettes. Evaluation Review, 17, 1 (1992), 82-92.

80. Lea, M., and Spears, R. Paralanguage and social perception in computer-mediated communication. Journal of Organizational Computing, 2, 3-4 (1992), 321-341.

81. Leimeister, J.; Ebner, W.; and Krcmar, H. Design, implementation, and evaluation of trust-supporting components in virtual communities for patients. Journal of Management Information Systems, 21, 4 (Spring 2005), 101-131.

82. Lewicki, R.J., and Bunker, B.B. Trust in relationships: A model of trust development and decline. In B.B. Bunker and J.Z. Rubin (eds.), Conflicts, Cooperation, and Justice. San Francisco: Jossey-Bass, 1995, pp. 133-173.

83. Lewicki, R.J., and Bunker, B.B. Developing and maintaining trust in work relationships. In R.M. Kramer and T.R. Tyler (eds.), Trust in Organizations: Frontiers of Theory and Research. Thousand Oaks, CA: Sage, 1996, pp. 114-139.

84. Limayem, M., and Hirt, S. How habit limits the predictive power of intention: The case of information systems continuance. MIS Quarterly, 31, 4 (2007), 705-737.

85. Lord, C.G.; Ross, L.; and Leper, M.R. Biases assimilation and attitude polarization: The effects of prior theories on subsequently considered evidence. Journal of Personality and Social Psychology, 37, 11 (1979), 2098-2109.

86. Louden, W., and Wildy, H. "Circumstance and proper timing": Context and the construction of a standards framework principals' performance. Educational Administration Quarterly, 35, 3 (1999), 398-422.

87. Lowry, P.B.; Vance, A.; Moody, G.; Beckman, B.; and Read, A. Explaining and predicting the impact of branding alliances and Web site quality on initial consumer trust of e-commerce Web sites. Journal of Management Information Systems, 24, 4 (Spring 2008), 199-224.

88. Mackie, D.M., and Cooper, J. Attitude polarization: The effects of group membership. Journal of Personality and Social Psychology, 46, 3 (1984), 575-585.

89. Maheswaran, D., and Chaiken, S. Promoting systematic processing in low-motivation settings: Effect of incongruent information on processing and judgment. Journal of Personality and Social Psychology, 61, 1 (1991), 13-25.

90. Malhotra, D. Trust and reciprocity decision: The differing perspectives of trustors and trusted parties. Organizational Behavior and Human Decision Processes, 94, 2 (2004), 61-73.

91. Malhotra, N.K.; Kim, S.S.; and Patil, A. Common method variance in IS research: A comparison of alternative approaches and a reanalysis of past research. Management Science, 52, 12 (2006), 1865-1883.

92. March, J.G. A Primer on Decision Making. New York: Free Press, 1994. 
93. Mayer, R.C., and Davis, J.H. The effect of the performance appraisal system on trust for management: A field quasi-experiment. Journal of Applied Psychology, 84, 1 (1999), $123-136$.

94. Mayer, R.C.; Davis, J.H.; and Schoorman, F.D. An integrative model of organizational trust. Academy of Management Review, 20, 3 (1995), 709-734.

95. McAllister, D.J. Affect- and cognition-based trust as foundations for interpersonal cooperation in organizations. Academy of Management Journal, 38, 1 (1995), 24-59.

96. McDonough, E.F., III; Kahn, K.B.; and Barczak, G. An investigation of the use of global, virtual, and collocated new product development teams. Journal of Product Innovation Management, 18, 2 (2001), 110-120.

97. McKnight, D.H.; Choudhury, V.; and Kacmar, C. Developing and validating trust measures for e-commerce: An integrative typology. Information Systems Research, 13, 3 (2002), 334-359.

98. McKnight, D.H.; Cummings, L.L.; and Chervany, N.L. Initial trust formation in new organizational relationships. Academy of Management Review, 23, 3 (1998), 473-490.

99. Meyerson, D.; Weick, K.E.; and Kramer, R.M. Swift trust and temporary groups. In R.M. Kramer and T.R. Tyler (eds.), Trust in Organizations: Frontiers of Theory and Research. Thousand Oaks, CA: Sage, 1996, pp. 166-195.

100. Morand, D. Dominance, deference, and egalitarianism in organizational interaction: A socio-linguistic analysis of power and politeness. Organization Science, 7, 5 (1996), 544-556.

101. Murphy, K.R.; Herr, B.M.; Lockhart, M.C.; and Maguire, E. Evaluating the performance of paper people. Journal of Applied Psychology, 71, 4 (1986), 654-661.

102. Nakayachi, K., and Watabe, M. Restoring trustworthiness after adverse events: The signaling effects of voluntary "hostage posting" on trust. Organizational Behavior and Human Decision Processes, 97, 1 (2005), 1-17.

103. Neter, J.; Kutner, M.H.; Nachtsheim, C.J.; and Wasserman, W. Applied Linear Statistical Models, 4th ed. Chicago: Irwin, 1996.

104. Norman, P.; Clark, T.; and Walker, G. The theory of planned behavior, descriptive norms, and the moderating role of group identification. Journal of Applied Social Psychology, 35, 5 (2005), 1008-1029.

105. Nunnally, J. Psychometric Theory, 2d ed. New York: McGraw-Hill, 1978.

106. Oakes, P.J., and Turner, J.C. Social categorization and intergroup behavior: Does minimal intergroup discrimination make social identity more positive? European Journal of Social Psychology, 10, 3 (1980), 295-301.

107. Oh, W., and Pinsonneault, A. On the assessment of the strategic value of information technologies: Conceptual and analytical approaches. MIS Quarterly, 31, 2 (2007), 239-265.

108. O'Hara-Devereaux, M., and Johansen, R. Global Work: Bridging Distance, Culture, and Time. San Francisco: Jossey-Bass, 1994.

109. Otten, S., and Moskowitz, G. Evidence for implicit evaluative in-group bias: Affectbiased spontaneous trait inference in a minimal group paradigm. Journal of Experimental Social Psychology, 36, 1 (2000), 77-89.

110. Pagell, M., and LePine, J.A. Multiple case studies of team effectiveness in manufacturing organizations. Journal of Operations Management, 20, 5 (2002), 619-639.

111. Paetzold, R.L.; Dipboye, R.L.; and Elsbach, K.D. A new look at stigmatization in and of organizations. Academy of Management Review, 33, 1 (2008), 186-193.

112. Paul, D.L., and McDaniel, R.R. A field study of the effect of interpersonal trust on virtual collaborative relationship performance. MIS Quarterly, 28, 2 (2004) 183-227.

113. Pavlou, P.A. Consumer acceptance of electronic commerce: Integrating trust and risk with the technology acceptance model. International Journal of Electronic Commerce, 7, 3 (2003), 101-134.

114. Piccoli, G., and Ives, B. Trust and the unintended effects of behavior control in virtual teams. MIS Quarterly, 27, 3 (2003), 365-395.

115. Pierce, C.A.; Aguins, H.; and Adams, S.K.R. Effects of a dissolved workplace romance and rater characteristics on responses to a sexual harassment accusation. Academy of Management Journal, 43, 5 (2000), 869-880.

116. Platt, L. Virtual teaming: Where is everyone? Journal of Quality and Participation, 22, 5 (1999), 41-44. 
117. Podsakoff, P.M., and Organ, D.W. Self-reports in organizational research: Problems and prospects. Journal of Management, 12, 2 (1986), 69-82.

118. Podsakoff, P.M.; MacKenzie, S.B.; Lee, J.Y.; and Podsakoff, N.P. Common method biases in behavioral research: A critical review of the literature and recommended remedies. Journal of Applied Psychology, 88, 5 (2003), 879-903.

119. Polzer, J.T.; Crisp, C.B.; Jarvenpaa, S.L.; and Kim, J.W. Extending the faultline model to geographically dispersed teams: How co-located subgroups can impair group functioning. Academy of Management Journal, 49, 4 (2006), 679-692.

120. Powell, W.W. Neither market nor hierarchy: Network forms of organization. In B.M. Staw and L.L. Cummings (eds.), Research in Organizational Behavior, vol. 12. Greenwich, CT: JAI Press, 1990, pp. 295-336.

121. Prentice, D.A., and Gerrig, R.G. Exploring the boundary between fiction and reality. In S. Chaiken and Y. Trope (eds.), Dual-Process Theories in Social and Cognitive Psychology. New York: Guilford, 1999, pp. 529-546.

122. Rabbie, J.M., and Horowitz, M. Arousal of ingroup-outgroup bias by a chance win or loss. Journal of Personality and Social Psychology, 13, 3 (1969), 269-277.

123. Rahman N. Caregivers' sensitivity to conflict: The use of vignette methodology. Journal of Elder Abuse and Neglect, 8, 1 (1996), 35-47.

124. Robert, L.P., and Dennis, A.R. Paradox of richness: A cognitive model of media choice. IEEE Transactions on Professional Communication, 48, 1 (2005), 10-21.

125. Robert, L.P.; Dennis, A.R.; and Ahuja, M.K. Social capital and knowledge integration in digitally enabled teams. Information Systems Research, 19, 3 (2008), 314-334.

126. Rotter, J.B. A new scale for the measurement of interpersonal trust. Journal of Personality, 35, 4 (1967), 651-665.

127. Rotter, J.B. Generalized expectancies for interpersonal trust. American Psychologist, 26, 5 (1971), 443-452.

128. Rotter, J.B. Interpersonal trust, trustworthiness, and gullibility. American Psychologist, 35, 1 (1980), 1-7.

129. Rousseau, D.M.; Sitkin, S.B.; Burt, R.S.; and Camerer, C. Not so different after all: A cross-discipline view of trust. Academy of Management Review, 23, 3 (1998), 393-404.

130. Russ, G.; Daft, R.L.; and Lengel, R.H. Media selection and managerial characteristics in organizational communications. Management Communication Quarterly, 4, 2 (1990), 151-175.

131. Schoorman, F.D.; Mayer, R.C.; and Davis, J.H. Empowerment in veterinary clinics: The role of trust in delegation. Working Paper, Department of Organizational Behavior and Human Resource Management, Purdue University, 1996.

132. Scott, B.A., and Colquitt, J.A. Are organizational justice effects bounded by individual differences? An examination of equity sensitivity, exchange ideology, and the big five. Group \& Organization Management, 32, 3 (2007), 290-325.

133. Shaw, J.C.; Wild, E.; and Colquitt, J.A. To justify or excuse? A meta-analytic review of the effects of explanations. Journal of Applied Psychology, 88, 3 (2003), 444-458.

134. Sheppard, B.H., and Tuchinsky, M. Micro-ob and network organization. In R.M. Kramer and T.R. Tyler (eds.), Trust in Organizations: Frontiers of Theory and Research. Thousand Oaks, CA: Sage, 1996, pp. 140-165.

135. Sitkin, S.B., and Pablo, A.L. Reconceptualizing the determinants of risk behavior. Academy of Management Review, 17, 1 (1992), 9-38.

136. Sitkin, S.B., and Weingart, L.R. Determinants of risky decision-making behavior: A test of the mediating role of risk perceptions and propensity. Academy of Management Journal, 38, 6 (1995), 1573-1592.

137. Sorrentino, R.M.; Holmes, J.G.; Hanna, S.E.; and Sharp, A. Uncertainty orientation and trust in close relationships: Individual differences in cognitive styles. Journal of Personal Sociology Psychology, 68, 2 (1995), 314-327.

138. Tajfel, H. Social psychology of intergroup relations. Annual Review of Psychology, 33, 1 (1982), 1-39.

139. Tajfel, H., and Turner, J.C. The social identity theory of intergroup behavior. In S. Worchel and W.G. Austin (eds.), Psychology of Intergroup Relations. Chicago: Nelson-Hall, 1986, pp. 7-24. 
140. Turner, J.C. Rediscovering the Social Group: A Self-Categorization Theory. Oxford: Blackwell, 1987.

141. Uzzi, B. Social structure and competition in interfirm networks: The paradox of embeddedness. Administrative Science Quarterly, 42, 1 (1997), 35-67.

142. Vidmar, N., and Rokeach, M. Archie Bunker's bigotry: A study in selective perception and exposure. Journal of Communication, 24, 1 (1974), 36-47.

143. Walther, J.B. Relational aspects of computer-mediated communication: Experimental observations over time. Organization Science, 6, 2 (1995), 186-203.

144. Walther, J.B. Group and interpersonal effects in international computer-mediated collaboration. Human Communication Research, 23, 3 (1997), 342-369.

145. Walther, J.B., and Burgoon, J.K. Relational communication in computer-mediated interaction. Human Communication Research, 19, 1 (1992), 50-88.

146. Wang, W., and Benbasat, I. Attributions of trust in decision support technologies: A study of recommendation agents for e-commerce. Journal of Management Information Systems, 24, 4 (Spring 2008), 249-273.

147. Wilder, D.A. Some determinants of the persuasive power of in-group and out-groups: Organization of information and attribution of independence. Journal of Personality and Social Psychology, 59, 6 (1990), 1202-1213.

148. Willemyns, M.; Gallois, C.; and Callan, V.J. Trust me, I'm your boss: Trust and power in supervisor-supervisee communication. International Journal of Human Resource Management, 14, 1 (2003), 117-127.

149. Wilson, J.M.; Straus, S.G.; and McEvily, B. All in due time: The development of trust in computer-mediated and face-to-face teams. Organizational Behavior and Human Decision Processes, 99, 1 (2006), 16-33.

150. Wood, W. Retrieval of attitude relevant information from memory: Effects on susceptibility to persuasion and on intrinsic motivation. Journal of Personality and Social Psychology, 42, 5 (1982), 798-810.

151. Xu, G.; Feng, Z.; Wu, H.; and Zhao, D. Swift trust in a virtual temporary system: A model based on the Dempster-Shafer theory of belief functions. International Journal of Electronic Commerce, 12, 1 (2007), 93-126.

152. Zahedi, F.M., and Song, J. Dynamics of trust revision: Using health infomediaries. Journal of Management Information Systems, 24, 4 (Spring 2008), 225-248.

153. Zolin, R.; Hinds, P.J.; Fruchter, R.; and Levitt, R.E. Interpersonal trust in cross-functional, geographically distributed work: A longitudinal study. Information and Organization, 14, 1 (2004), 1-26. 


\section{Appendix: The Vignette}

THIS APPENDIX PRESENTS THE VIGNETTE that was used for the e-mail treatment.

\section{Phase 1: The Project}

A group was recently assigned a class project. The project entailed building a Web site that provided information for graduate business school applicants and the assignment must be completed within roughly two weeks. In particular, this Web site should provide information about the graduate business schools, b-school rankings, and the GMAT (Graduate Management Admission Test), as well as a listserver for information exchange. All team members will receive the same grade, which will count for 5 percent of their semester grade.

The group consists of:

- Tom (who was identified as grounding-oriented) is a junior majoring in management at [name removed] University.

- Peter (who was identified as figural-oriented) is a junior majoring in management at [name removed] University.

- Jane (who was identified as figural-oriented) is a junior majoring in management at [name removed] University.

Since team members are located at different universities, all group communications were only through e-mails. No face-to-face meetings or telephone conversations were carried out.

\section{Phase 2: E-Mail Transcript}

Please read the following transcript. When you are finished, click the "Continue" button to proceed to the next page, which will ask you some questions about your reaction to what happened.

The following is a transcript of the daily e-mails between the group members.

Day 1

Jane: Hello, I'm Jane . . .

Peter: I am Peter. It's nice to meet you guys ...

Tom: Hi, everyone. I am Tom. I look forward to working with you all very much. And I'm sure we all need a good grade on this project . . . at least I do! So I think it's very important that we all work together. Do you guys want to begin assigning work now?

Tom: Well, who's going to write the text for the web pages? I'm not a very good writer. 
Jane: I guess I could . . . But let me be upfront with you guys! I'm kind of busy and this is not the most important thing in my life personally. But, I'll do my part.

Tom: Who is going to write the code for the web pages?

Day 2

Peter: I will . . I just bought a book on JAVA programming, and I learn quickly.

Tom: Great, but it's important that we have the web pages in their basic forms up and running by next week.

Peter: Sure, you have my word. They will be up and running by next week.

Jane: Tom, can you compile a list of links about b-schools and e-mail them to me by next week?

(Lack of response from Tom for a while ...)

Jane: Tom ... I hope you got my previous message about compiling a list of links about b-schools. Could you e-mail them to me by next week?

Tom: Sounds good ... I'll e-mail them to you by next week ...

Day 9

Tom: The written text for the web pages doesn't flow!

Peter: It looks O.K. to me ... .

Jane: Guys ... I said that I was going to do it and I did it. This is as good as it gets. By the way . . . Tom, I haven't gotten the links yet . . . You said you were going to e-mail them to me. I don't think anything is wrong with my e-mail server. Did you send them?

Day 10

Tom: SEND WHAT??

Jane: The links to the web pages of top business schools.

Tom: Did I say that I was going to do that? I'm sorry . . . I must have forgotten that I said I would do that ...

Peter: Tom, you did promise that you would e-mail the links last week. And, guys ... I will have the web pages up and running by tonight.

Day 11

Tom: Peter, I haven't seen the web pages online yet ...

Peter: I haven't started yet, but it shouldn't take me long.

Tom: But you e-mailed us last night and said that the pages were completed and online.

Peter: I'm sorry ... I thought I could have it done by now.

Tom: E-mail me the code you have so far and I will finish it ... 
Peter: Thanks, but no thanks; I'll do it.

Jane: Hey, guys . . I I already got a solid B+ in this class! So if you guys want to slack off . . that will be O.K. with me. And, Tom, don't worry about the links. I'll pull some up later. Are you pretty good with databases? Because I'm not!

Tom: Not really . . . but I am willing to try!!!

Jane: In that case, why don't you set-up the database for the e-mail entries?

Tom: Sure!! Remember that we only have one two more days to finish this assignment. If we work together, we can get this done.

Day 13

Jane: Peter, the pages load perfectly ...

Tom: Yeah, I'm really impressed with the web pages, Peter.

Peter: No problem. I am pretty good at programming.

Jane: Guys, we still have to put the database online.

Tom: Ooooh ... I finally figured out how to make the database work ... I'm afraid that I'm not very good with computers.

Peter: Well, guys, I cannot do any more work tonight. I promised my girl that I would take her to the Big Ten shootout. The attached file has the code I have so far ... Good luck!!

Jane: Thanks, Peter. But, I wish you had told us earlier that you will not have time tonight. Now, Tom and I will have to work all night by ourselves to set everything up before the deadline tomorrow.

Jane: Tom, let's get real ... This project is going to be late ... I personally have other things to do tonight that are more important than this project.

Tom: Well . . I'll set everything up. I feel bad about not being able to initially complete the database. And I think it still needs more work anyway. I don't want anyone to get a lower grade because the project is late. And I really want us to get a good grade on this assignment. So I'll finish it ...

\section{Phase 3: A New Project}

Imagine that you were assigned to this team and this team was recently assigned a class project. The project entailed building a Web site that provided information for graduate engineering school applicants and the assignment must be completed within two weeks, with no exception. In particular, this Web site should provide information about the graduate engineering schools, engineering schools rankings, and the GRE (Graduate Record Exam), as well as a list server for information exchange. All team members will receive the same grade. However, it counts for 15 percent of your semester grade, but counts for only 5 percent of the semester grades of your team members.

Again, since team members are located at different universities, all group communications [will only be] through e-mails. No face-to-face meetings or telephone conversations [will be] permitted. 
Copyright of Journal of Management Information Systems is the property of M.E. Sharpe Inc. and its content may not be copied or emailed to multiple sites or posted to a listserv without the copyright holder's express written permission. However, users may print, download, or email articles for individual use. 